\title{
Probabilistic Tsunami Hazard Model of Building Inundation Following a Subaqueous Volcanic Explosion Based on the 1716 Tsunami Scenario in Taal Lake, Philippines
}

Kwanchai Pakoksung ( $\square$ pakoksung@irides.tohoku.ac.jp )

Tohoku Daigaku

Anawat Suppasri

Tohoku Daigaku

Fumihiko Imamura

Tohoku Daigaku

\section{Research Letter}

Keywords: tsunami, Philippines, inundation, volcanic explosion

Posted Date: June 29th, 2020

DOI: https://doi.org/10.21203/rs.3.rs-38052/v1

License: (c) (1) This work is licensed under a Creative Commons Attribution 4.0 International License.

Read Full License 
Probabilistic Tsunami Hazard Model of Building Inundation Following a Subaqueous Volcanic Explosion Based on the 1716 Tsunami Scenario in Taal Lake, Philippines

\author{
K. Pakoksung ${ }^{(1)}$, A. Suppasri ${ }^{(2)}$, F. Imamura ${ }^{(3)}$ \\ (1) Postdoctoral researcher, International Research Institute of Disaster Science, Tohoku University, \\ pakoksung@irides.tohoku.ac.jp \\ (2) Associate Professor, International Research Institute of Disaster Science, Tohoku University, \\ suppasri@irides.tohoku.ac.jp \\ (3) Professor, International Research Institute of Disaster Science, Tohoku University, imamura@irides.tohoku.ac.jp
}

\begin{abstract}
A probabilistic hazard analysis of a tsunami generated by a subaqueous volcanic explosion is performed for Taal Lake in the Philippines. The Taal volcano in Taal Lake is an active volcano on Luzon Island in the Philippines, and its eruption would have a strong impact on humans around the coastal area of the lake. This study aims to develop a probabilistic tsunami hazard model of inundated buildings for tsunami mitigation in future scenarios. To develop the probabilistic tsunami hazard model, different explosion diameters were used to generate tsunamis of different magnitudes in the TUNAMI-N2 model. The initial water level in the tsunami model was estimated based on the explosion energy as a function of the explosion diameter. The tsunami-induced inundation from the TUNAMI-N2 model was overlaid on the distribution of buildings. The statistical distribution of inundated buildings can be modeled with the lognormal distribution, which exhibits the best fit among nine candidate statistical distributions. The tsunami hazard analysis is explained by using the conditional hazard curve and map. These products were used to calculate the probability of building inundation given the occurrence of a subaqueous explosion. The results from this study can be used for future tsunami mitigation in the case of a tsunami generated by a subaqueous volcanic explosion.
\end{abstract}

\title{
1. Introduction
}

Tsunamis generated by subaqueous volcanic eruptions represent only a few of all recorded tsunamis, which are more commonly generated by earthquakes or landslides. However, a tsunami can be generated by an eruption, and the surface water and tsunami hazards related to subaqueous eruptions are principally interesting to evaluate and forecast because there is a lack of geographical, observational, and contributory data. For example, in Taal Lake in the Philippines, as shown in Figure 1, tsunamis are related to the initial water level and the large-scale resonance within the lake (Ichinose et al. 2000; Freundt et al. 2007; Paris and Ulvrova 2019).

The Taal volcano has produced 33 historical eruptions, and 5 notable eruptions generated tsunamis in the lake in 1716, 1749, 1754, 1911 and 1965 (Delos Reyes et al. 2018; Paris and Ulvrova 2019). The 1716 eruption was a subaqueous volcanic explosion that was located in the southern basin of the caldera and near the southern point of Taal Island. The large ground motion lifted the water in the lake, forming a wave that impacted the shores. The maximum inundation in the southwestern area reached a height of approximately $17 \mathrm{~m}$ on land (Paris and Ulvrova 2019). The 1749 eruption clearly produced a wave in response to the violent level-4 phreatomagmatic eruption (Delos Reyes et al. 2018; Paris 
and Ulvrova 2019). This wave impacted the northern shores of the lake, and the eruption point was located north of Taal Island. The 1754 event killed 20 people through building collapse induced by waves on the western shore of the lake (Paris and Ulvrova 2019). Thus, observations clearly indicated the existence of a tsunami wave during this event. The phreatomagmatic to phreatoplinian eruption in 1911 occurred on Taal Island. A tsunami with a wave height of approximately $3 \mathrm{~m}$ affected villages on the western shore of the lake, and 30 people drowned (Paris and Ulvrova 2019). The 1956 eruption was also a phreatomagmatic eruption that generated a new crater on the southwestern flank of the island (Delos Reyes et al. 2018). In total, 300 fatalities occurred when tsunami waves impacted the western shore of the lake, with a wave runup of $4.7 \mathrm{~m}$ above the mean level of the lake (Moore et al. 1966). In 2020, the Taal volcano erupted on January 12, and the eruption occurred in the main crater, with a lava fountain height of $500 \mathrm{~m}$ (Cartier 2020). Ash from this eruption spread around the volcano, reaching distances of approximately $10-15 \mathrm{~km}$, but there were no reports of a tsunami in Taal Lake during this event. According to the small eruption in Taal Lake in 2020, we have concentrated on future tsunami hazards in this area for future tsunami disaster management. To mitigate future tsunami disasters, the probabilities of various scenarios that could occur in the area have been estimated (Li et al 2016; Li et al. 2018; Paris et al. 2019). In this study, we aim to determine the probability that tsunami hazards will impact urbanizing areas in response to subaqueous volcanic explosions in Taal Lake for stakeholders and policymakers.

The characteristics of a tsunami generated by a subaqueous volcanic explosion, such as in the case of the 1716 eruption in Taal Lake, is controlled by several physical parameters, such as water depth, size of the eruption vent, depth and energy of the explosion, and magma-water interaction, which are used to define the explosion itself (as explained in detail in Le Mehaute 1971; Kokelaar 1986; Wohletz 1986; Mirchina and Pelinovsky 1988; Duffy 1992; Le Mehaute and Wang 1996; Kedrinskii 2005; Egorov 2007; Morrissey et al. 2010; Paris and Ulvrova 2019). The explosion forms an initial crater, resulting in a similar cavity at the water surface, with a cylindrical bore. The cylindrical bore expands radially to form the leading wave, followed by a wave trough. The initial water surface displacement, corresponding to the maximum height of the bore, can be empirically calculated as a function of the explosion energy. The explosion is controlled by the water depth and the size of the eruption vent (see details in Le Mehaute 1971; Sato and Taniguchi 1997; Goto et al. 2001; Paris and Ulvrova 2019). The initial water displacement downward follows the upward displacement and forms a steep cone in the center of the bore. The cone collapses and generates a second bore, as explained by the experimental explosion and numerical models in previous studies (Le Mehaute and Wang 1996; Kedrinskii 2005; Torsvik et al. 2010; Ulvrova et al. 2014; Paris and Ulvrova 2019).

Several methods of probabilistic tsunami hazard analysis (PTHA) have been developed during this decade (Grezio et al. 2017). PTHA is based on the probable values of tsunami parameters, such as tsunami height, flow velocity, flow depth, runup height, or inundation extent, to be exceeded at a particular location within a given period. The PTHA can integrate geographical, historical, and experimental data on both tsunamis and tsunami sources using statistical and numerical methods. 
However, PTHA methods for a volcanic source of tsunamis are more limited than those for an earthquake source (Grezio et al. 2017). Here, tsunamis are produced by a volcanic source, and this work focuses on a conditional PTHA in which the volcanic mechanism has the potential to generate a tsunami from a subaqueous explosion.

In this study, tsunamis generated by a subaqueous explosion were considered under different scenarios in Taal Lake (Luzon Island, Philippines). The scenarios vary in the size of the eruption, with the eruption location confined to that of the 1716 event, which represents one of the largest submarine explosions in the lake. Previous studies have focused only on tsunami hazard assessment and mapping, while tsunami hazard assessment involving building exposure has not been studied. Thus, to address this gap, we first prepare a probabilistic tsunami inundation model of building exposure based on different scenarios of subaqueous explosion-induced tsunamis affecting the coastal area around the lake.

The paper is presented as follows: the methodology is explained in section 2 . The beginning of section 2 presents the hypothesis that a subaqueous explosion generates an initial water level for tsunami propagation (section 2.1). Then, the tsunami modeling is described in section 2.2. The probability of hazard analysis is explained in section 2.3. Finally, the modeling results are presented in section 3, the results are discussed in section 4 , and conclusions are presented in section 5.

\section{Methodology}

The methodology presented in this paper is based on using the Monte Carlo technique (Li et al. 2016) to quantify the tsunami hazard posed to buildings in a subaqueous explosion scenario. This method is based on 4 steps. First, the Monte Carlo method involved identifying the potential vent area (explosion size). The vent diameter, according to Paris and Ulvrova (2019), was approximately $600 \mathrm{~m}$, and the submerged volcanic cone (vent size) was assumed to be the same size. For this study, we varied the vent diameter from 100 - 1000 m into 99 scenarios as conditional scenarios with an eruption location corresponding to the position of the 1716 event. Second, the 99 scenarios were used to generate the initial water level by using the method explained in section 2.1. Third, the initial water levels of the 99 scenarios were used to simulate the tsunami waves reaching the shores of Taal Lake. The tsunami modeling also incorporates the effect of building (i.e., the friction of surface resistance) into the model (see detail in section 2.2). The modeled buildings in this study were extracted from OpenStreetMap (OSM) though QGIS software. Fourth, the conditional probability of each demonstrative scenario was calculated and combined with the building inundation results for each simulated tsunami scenario to present the PTHA for exposed buildings. In this step, we used 10 candidate distributions to verify the best fit of the probability modeling of the number of inundated buildings, as presented in detail in section 2.3 .

\subsection{Model of subaqueous explosion and tsunami generation}

We selected 99 different sizes of simulated explosions in Taal Lake with the eruption location 
corresponding to the location of the 1716 subaqueous eruption. The energy of an explosion can be estimated with the empirical formula provided by Sato and Taniguchi (1997).

$$
E=4.45 \times 10^{6} D^{3}
$$

where $E$ is the explosion energy in Joules and $D$ is the diameter of the vent area in meters. The explosion energy generates an initial surface displacement, as described by Torsvik et al. (2010) and Ulvrova et al. (2014, 2016). A parabolic cavity with a vertical steep rim, representing the size of the water cavity $\left(R_{c}\right)$ in meters, can be calculated based on the explosion energy as follows:

$$
R_{c}=0.0361 E^{0.25}
$$

The estimation of the maximum initial water level is related to the explosion energy and water depth of the explosion $d$ in the empirical function presented by Le Mehaute and Wang (1996).

$$
\eta_{0}=c E^{0.24}
$$

where $\eta_{0}$ is the vertical initial surface displacement, corresponding to the maximum initial water level, in meters, $E$ is the energy of the explosion in Joules, and $c$ is a constant that is a function of the energy of the explosion and water depth (Le Mehaute and Wang 1996). The constant is assumed to have one of two values: (1) $c=0.0143$ if $6.15 \times 10^{-4}<d / E^{1 / 3}<1.85 \times 10^{-2}$ and (2) $c=0.0291$ if $E<6.15 \times 10^{-4}$. The distribution of water surface displacement from the crater $(\eta)$ is based on the maximum initial water level $\left(\eta_{0}\right)$ using the following equation (Le Mehaute and Wang 1996; Maeno and Imamura 2011):

$$
\begin{aligned}
& \text { if } r_{e} \leq R_{c}, \eta=\eta_{0}\left[2 \frac{r_{e}}{R_{c}}-1\right] \\
& \text { if } r_{e}>R_{c}, \eta=0
\end{aligned}
$$

where $r_{e}$ is the distance from the explosion center in meters.

\subsection{Numerical simulation of a tsunami}

To obtain the tsunami inundations for different explosion sizes, a numerical tsunami simulation was driven with the TUNAMI-N2 model (Imamura 1995; Goto et al 1997). The TUNAMI-N2 model was first developed at Tohoku University to model tsunami propagation and inundation on land and operates using the nonlinear theory of the shallow water equation, which is solved using a leap-frog scheme. The nonlinear shallow water equation is presented as Equations $6-8$, wherein the finite difference method is applied to run the nonlinear equation with a bottom fiction represented by Manning's roughness coefficient.

$$
\begin{gathered}
\frac{\partial \eta}{\partial t}+\frac{\partial M}{\partial x}+\frac{\partial N}{\partial y}=0 \\
\frac{\partial M}{\partial t}+\frac{\partial}{\partial x}\left(\frac{M^{2}}{D}\right)+\frac{\partial}{\partial y}\left(\frac{M N}{D}\right)+g D \frac{\partial \eta}{\partial x}+\frac{g n^{2}}{D^{\frac{7}{3}}} M \sqrt{M^{2}+N^{2}}=0 \\
\frac{\partial N}{\partial t}+\frac{\partial}{\partial x}\left(\frac{N M}{D}\right)+\frac{\partial}{\partial y}\left(\frac{N^{2}}{D}\right)+g D \frac{\partial \eta}{\partial y}+\frac{g n^{2}}{D^{\frac{7}{3}}} N \sqrt{M^{2}+N^{2}}=0
\end{gathered}
$$


where $\eta$ is the water level, $M$ and $N$ are the fluxes of water in the $x$ and $y$ directions, $D$ is the total depth, $g$ is gravitational acceleration, and $n$ is Manning's roughness coefficient. The preparation process was performed for the bathymetry grid for the tsunami propagation and inundation simulations.

In the TUNAMI-N2 model, buildings are represented by the roughness as a function of the drag coefficient in the last term in Equations 7 and 8. The coefficient is evaluated by the setting the roughness coefficient to that of surface types other than buildings. The composite equivalent roughness coefficient from other surface types and buildings is estimated by using Equation 9, which has been explained with the concept of the flow resistance induced by large ground objects (Copeland 2000; Dutta et al.2007; Aburaya and Imamura 2002). This equation is related to the density of buildings and the flow depth, and the roughness increases as the flow depth increases.

$$
n^{2}=\frac{(100-\theta)}{100} n_{0}^{2}+(C D / 2 g W) \frac{\theta}{100} D^{4 / 3}
$$

where $n_{0}$ is Manning's roughness coefficient for surface types other than buildings, $\theta$ is the density of buildings in the computation grid as a percentage, $C D$ is the drag coefficient and is set to 1.5 (FEMA 2003; Koshimura et al. 2009), $W$ is the horizontal scale of the buildings in meters, and $D$ is the total depth in meters.

All numerical simulations were performed by using the TUNAMI-N2 model based on a 1145 x 1171 grid with a resolution of $30 \mathrm{~m}$. The grid was achieved by combining bathymetry and topography; the bathymetry was digitized from Ramos (2002), and the topography was collected from the Shuttle Radar Topography Mission (SRTM, Farr et al. 2007). The computational domain was used to perform a constant-grid tsunami simulation, which yielded 11 million equations and unknowns to be solved at each time step of $0.01 \mathrm{~s}$, and applied the Open Multi-Processing (OpenMP) platform to achieve a more rapid computation time. At the boundaries, the open sea featured nonreflective boundary conditions, and the shore areas had no specific boundary conditions for wet/dry fronts (Imamura, 1995). Note that the simulated grid without buildings was assigned a constant Manning's coefficient of 0.025 .

Building shapes were collected from OpenStreetMap (OSM) though QGIS open-source software as shown in Figure 1. In this study, we analyzed buildings in an area close to the shore of Taal Lake within a distance of approximately $2 \mathrm{~km}$. The shapes of the collected buildings were overlaid on the computation grid to estimate the building area percentage in each grid. The building percentage is used to estimate the roughness in Equation 9, and the building location is used to determine the maximum flow depth for probability hazard analysis in section 2.3 .

\subsection{Probabilistic hazard analysis}

For each scenario, the maximum inundation depth at all inland computation grids was estimated by subtracting the topography (from SRTM DEM) data from the simulated maximum water level. The inundation depth map from the 99 scenarios of the explosion area was overlaid on the building locations from the OSM data to determine the inundated buildings. The inundated buildings were 
counted in each inundation depth range.

The probability of explosion size in this study is based on the vent diameter in the 99 scenarios. The distribution function reveals a decreasing probability of increasing explosion size. For example, the $1^{\text {st }}$ scenario features the smallest explosion size with a probability value of 1 . The $99^{\text {th }}$ scenario features the largest explosion size and a probability value of approximately 0.01 .

Hazard curves were established based on the total number of inundated buildings and each depth range. The curve for each scenario is described by the best-fit distribution among 9 candidate statistical distributions. The 9 candidate distributions were beta, exponential, gamma, lognormal, normal, Pearson type III, triangular, uniform, and Weibull distributions, the details of each distribution have previously been explained by Pakoksung and Takagi (2017). The parameter in each candidate distribution was estimated by the maximum likelihood estimation (MLE) method, which is commonly used to optimize the coefficient in statistical methods (Myung 2003; Pakoksung and Takagi 2017). The goodness-of-fit (GOF) test describes how well a statistical distribution fits referenced data. The nine distributions were presented by the cumulative distribution function (CDF) using the parameter from MLE. The GOF test measures discrepancies between referenced and predicted values (Maydeu-Olivares 2013). In this study, the chi-square test was used to evaluate the GOF test to screen out unsuitable distributions (Pakoksung and Takagi 2017). The chi-square test is used to compare the statistical distribution and hypothesis tests. The test is a nonparametric statistical test that is used to determine whether two data points are either independent or dependent. The test is defined as

$$
\chi^{2}=\sum_{i=1}^{k} \frac{\left(O_{i}-E_{i}\right)^{2}}{E_{i}}
$$

where $O_{i}$ is the referenced frequency for bin $i$ and $E_{i}$ is the expected frequency for bin $i$.

\section{Results}

\subsection{Tsunami wave generation and inundation extent}

Numerical tsunami simulation results from 99 scenarios are presented in this section. The maximum tsunami amplitude and inundation area from numerical modeling were calculated from terrain data with a grid size of $30 \mathrm{~m}$ for a simulation time of 60 minutes. The 99 scenarios of explosions with vent diameters varying from 100 to $1000 \mathrm{~m}$ (which control the probability of occurrence) are presented in Figure 2a. The conditional probability values in Figure 2a indicate that the highest probability is associated with the smallest vent size (small hazard) and that the lowest probability is associated with the largest vent size (greatest hazard). Based on Equation 1, the vent sizes correspond to the explosion energies of $1 \times 10^{15}$ to $35 \times 10^{15} \mathrm{~J}$, as explained in Figure $\mathbf{2 b}$. Figure $2 \mathbf{c}$ presents the relationship between the explosion energy and the maximum initial water level based on Equation 3. The calculated initial water levels vary from 25 to $135 \mathrm{~m}$ for the lowest and highest explosion energies of the assumed scenarios, respectively.

Tsunami generation was based on the maximum initial water level and size of the water cavity, and the 
diameter of the cavity was calculated with Equation 2. The distribution of the initial water level was identified as a parabolic shape that was generated with Equations 4 and 5. Figure 3 presents the tsunami generation in the $99^{\text {th }}$ scenario with a vent diameter of $1000 \mathrm{~m}$ and a maximum initial water level of $135 \mathrm{~m}$; the propagation is shown at the different times, namely, $0 \mathrm{~s}, 10 \mathrm{~s}, 30 \mathrm{~s}$, and $60 \mathrm{~s}$. The tsunami initially features a parabolic shape, after which the second wave forms and moves from the center of the explosion point.

Figure 4 presents the maximum water level after 60 minutes in the tsunami model for three different scenarios, namely, the $1^{\text {st }}, 50^{\text {th }}$, and $90^{\text {th }}$ scenarios, as well as the maximum amplitude distribution in the lake. The difference between the maximum water level and the topography reflects the inundation extent and flow depth based on the runup process. The right column in Figure 4 shows the inundation extent in the three different scenarios and its overlap with the buildings. The $99^{\text {th }}$ scenario is the greatest hazard scenario and produces the largest inundation area in this study.

The inundated area and buildings are presented in Figure 5. The relationship between the maximum initial water level and the inundated area can be seen in Figure 5a: the increase in the inundation area was dependent on the increase in the maximum initial water level. Additionally, the number of inundated buildings increases with the increase in the inundation area, as can be observed in Figure $\mathbf{5 b}$. The maximum initial water level of $25 \mathrm{~m}$ in the $1^{\text {st }}$ scenario, the lowest of the water levels, generates an inundation area of approximately $1.5 \mathrm{~km}^{2}$ and inundates 3500 buildings. On the other hand, the greatest hazard (the 99th scenario) generates an inundation area of approximately $69 \mathrm{~km}^{2}$ and inundates approximately 11500 buildings.

\subsection{Probabilistic condition hazard assessment of inundated buildings}

We have produced tsunami hazard maps and curves of building exposure in which the scenarios are conditional on the magnitude of the subaqueous explosion based solely on the vent size. The number of inundated buildings was first counted based on the inundation depth, and the results are represented with a histogram. Then, the histogram was compared to the nine candidate statistical distributions mentioned in the methodology. The best-fit distribution was evaluated with the chi-square test and was selected based on the minimum value of the test. Finally, the parameter of the best-fit distribution was used to model the hazard curve to determine the relationship between probability and the cumulative number of inundated buildings in each inundation depth range. Additionally, the hazard map was estimated by overlaying all 99 scenarios and counting how many buildings were inundated to generate the hazard curve.

A building hazard map for some example scenarios is shown in Figure 6. This reveals that the inundation depth of the buildings increases depending on the level of hazard. For example, considering the same building, the 1st scenario (the smallest hazard in Figure 6a) has a lower water depth than the 99th scenario (the greatest hazard in Figure 6e). The number of inundated buildings in each scenario was used to develop the probability hazard assessment, which is the goal of this study.

Figure 7 shows the number of inundated buildings represented by the histogram for some examples of 
scenarios. In all scenarios, the highest number of the inundated building corresponds to low inundation depths between 1 and $10 \mathrm{~m}$. For example, the peak of the 1st scenario is at a water depth of approximately $1 \mathrm{~m}$, while the peak of the 99th scenario is at a water depth of approximately $5 \mathrm{~m}$. According to the model, application of the nine statistical distributions to the inundated buildings in each inundation depth range can be observed in Figure 7, which shows a comparison between the observed and predicted data. As shown in Figure 7c, the lognormal and Pearson-III distributions can capture the peaks of the reported scenarios.

A chi-square test was used to identify the best-fit statistical distribution among the nine candidate distributions to predict the probability hazard curve. Figure 8 shows the comparison of the nine candidate statistical distributions. The lognormal distribution is the best-fit distribution among the nine distributions for all scenarios, followed by Pearson-III and Weibull as second and third, respectively. The lognormal distribution has also been used to model collapsed buildings due to tsunamis in several events, such as the 2004 Indian Ocean tsunami (Koshimura et al. 2009; Suppasri et al. 2011) and the large 2011 Pacific Ocean tsunami (Suppasri et al. 2013; Fukutani et al. 2018). The parameters of the distribution explained the relationship between the cumulative number of inundated buildings and the inundation depth. Hence, the lognormal distribution of each scenario was used to create the hazard curve, as presented in Figure 9. As seen in the figure, all scenario curves feature a noticeably different number of inundated buildings with the same inundation depth. Then, all scenario curves were combined to model the probabilistic relationship in Figure 2a. The probability hazard curve was generated, as shown in Figure 10c, and the curve was extended to 0.001. Furthermore, the probability hazard maps of inundation area are presented in Figures 10a and 10b, while the probability hazard map of inundated buildings is shown in Figure 10d. Both probability hazard curves are the main results of the PTHA of this study and are presented as conditional hazards based on the 99 scenarios.

These final results can be useful for stakeholders on the local side and policymakers on the government side. Stakeholders can use the probability map to be more aware of the hazard level of their own residential areas, and the map might also be a useful tool in an evacuation. For example, if a house is located in a zone with a probability of 1 , the people in the house need to evacuate immediately to a safe zone when a tsunami occurs. In contrast, if the probability of a house is approximately 0.01 , the people in the house may need to evacuate only in some limited situations. Policymakers can apply this map for planning the residential tsunami safety zone for future tsunami prevention, and they can also use the map for estimating the direct disaster losses immediately when a tsunami occurs.

\section{Discussion}

Tsunami hazards related to subaqueous volcanic explosions in Taal Lake are far from insignificant, although the probability of an eruption at the bottom of the lake in the caldera is rather low. To consider the largest eruption scenario (the 99th scenario), with a tsunami hazard probability of 0.01, the highest wave amplitude of approximately $50 \mathrm{~m}$ occurs in the eastern area, while the lowest wave 
amplitude of approximately $20 \mathrm{~m}$ occurs in the northwest area. This scenario created a runup wave on land that inundated an area of approximately $70 \mathrm{~km}^{2}$, including approximately 11500 buildings. On the other hand, the smallest explosion scenario (the 1st scenario), with a tsunami hazard probability of 1 , presents a small hazard, with an inundation area of approximately $1.5 \mathrm{~km}^{2}$, including 3500 inundated buildings. The simulation results were limited by the 30-m resolution for the bathymetry and topography.

Tsunamis observation data from the history of eruptions are limited in terms of providing constraints on the wave height and inundation depth. According to records on the 1716 submarine explosion, the wave inundated the southwestern shore of the lake and reached a height of up to $17 \mathrm{~m}$ on land. This submarine explosion event can be assumed to correspond to the 50th scenario in this study because the event had a moderate explosion size. In this study, we provide the probability of a subaqueous volcanic explosion generating a tsunami in Taal Lake with a conditional probability of hazard occurrence. The conditional probability of the tsunami hazard in this study does not yet represent the real explosion probability based on observation data; however, in the future, when the real explosion probability is computed, the conditional probability of this study can be scaled to represent the real probability of a subaqueous volcanic explosion generating a tsunami in Taal Lake.

In this research, tsunami propagation in the lake and on the shore, such as wave breaking and nonhydrostatic pressure terms, were not simulated because of the high computational cost. Another limitation is associated with the model of the explosion itself: a vent with a given size produces a more powerful explosion at shallow depths (Goto et al. 2001, Taddeucci et al. 2010). While the morphology of the crater might be influenced by a combination of vertical and horizontal explosion (Valentine et al. 2012, 2015), the vent size assumption for explosion magnitude might result in an overestimation in some scenarios. We consider variability only in the vent size, and the only modeled explosion location corresponds to that of the 1716 event in the study area. Studying random variations in the explosion location has been recommended by Paris and Ulvrova (2019). In this paper, we focused only on tsunamis generated by subaqueous volcanic explosions in Taal Lake. On the other hand, other sources, such as pyroclastic density currents flowing into the lake or landslides triggered by earthquakes, should be integrated into the probabilistic analysis to fill gaps in the tsunami hazard assessment, as explained in Grezio et al. (2015).

\section{Conclusion}

Taal is one of the active volcanoes located in Taal Lake on Luzon Island in the Philippines, and this volcano presents risk mitigation challenges to humans. In its history, eruptions have occurred in the central crater, such as the $1749,1754,1911$, and 1965 eruptions, while the 1716 eruption was a subaqueous volcanic explosion. We simulated different scenarios of subaqueous explosions based on the location of the 1716 event and the tsunami disaster related to this explosion. In this study, the conditional probability hazard assessment of tsunamis generated by subaqueous volcanic explosions is performed for Taal Lake. The scenarios all show that the tsunamis generated by subaqueous 
explosions have a large impact on the shores of the lake.

The inundated building hazard probability can be predicted by the lognormal distribution, which yielded the best fit among nine candidate statistical distributions. The results of this study, a tsunami hazard probability assessment, present an estimate of the probability of a tsunami hazard impacting urban areas following a subaqueous volcanic explosion in Taal Lake for stakeholders and policymakers. The stakeholders and policymakers can use the results for future tsunami mitigation in the case of a tsunami generated by a subaqueous volcanic explosion.

\section{Acknowledgments}

In this study, QGIS software was used to illustrate the spatial data and collect building data from OSM. This research was funded by the Willis Research Network (WRN) under the Pan-Asian/Oceanian tsunami risk modeling project through the International Research Institute of Disaster Science (IRIDeS) at Tohoku University.

\section{References}

Aburaya T, Imamura F (2002) The proposal of a tsunami run-up simulation using combined equivalent roughness. Annual Journal of Coastal Engineering JSCE 49:276-280 (in Japanese).

Cartier KMS (2020) Taal eruption and ashfall continue; thousands still at risk. Eos: 101. https://doi.org/10.1029/2020EO138679.

Delos Reyes PJ, Bornas MA, Dominey-Howes D, Pidlaoan AC, Magill CR, Solidum RU (2018) A synthesis and review of historical eruptions at Taal volcano, Southern Luzon, Philippines. Earth Sci Rev. 177:565-588.

Duffy DG (1992) On the generation of oceanic surface waves by underwater volcanic explosions. J Volcanol Geotherm Res 50:323-344.

Dutta D, Alam J, Umeda K, Hayashi M, Hironaka S (2007) A two-dimensional hydrodynamic model for flood inundation simulation: A case study in the lower Mekong river basin. Hydrological Processes 21:1223-1237.

Farr TG, Rosen PA, Caro E, Crippen R, Duren R, Hensley S, Kobrick M, Paller M, Rodriguez E, Roth L, Seal D, Shaffer S, Shimada J, Umland J, Werner M, Oskin M, Burbank D, Alsdorf D (2007) The shuttle radar topography mission. Rev Geophys 45:1-33.

Federal Emergency Management Agency (FEMA) (2003) Coastal Construction Manual (CCM), 3rd edn. (fema 55), p 296 .

Freundt A, Strauch W, Kutterolf S, Schmincke HU (2007) Volcanogenic tsunamis in lakes: examples from Nicaragua and general implications. Pure Appl Geophys. 164:527-545

Fukutani, Y., Suppasri, A., Imamura, F. (2018) Quantitative Assessment of Epistemic Uncertainties in Tsunami Hazard Effects on Building Risk Assessments. Geosciences. 8:17.

Goto A, Taniguchi H, Yoshida M, Ohba T, Oshima H (2001) Effects of explosion energy and depth to the formation of blast wave and crater: field explosion experiment for the understanding of volcanic 
explosion. Geophys Res Lett 28:4287-4290

Goto C, Ogawa Y, Shuto N, Imamura F (1997) IUGG/IOC time project, Numerical method of tsunami simulation with the leap- frog scheme, IOC Manuals and Guides, 35, U.N. Educ. Sci. Cult. Organ., Paris, pp 130.

Grezio A, Babeyko A, Baptista MA, Behrens J, Costa A, Davies G, Geist EL, Glimsdal S, Gonzàlez FI, Griffin J, Harbitz CB, LeVeque RJ, Lorito S, Lövholt F, Omira R, Mueller C, Paris R, Parsons T, Polet J, Power W, Selva J, Sörensen MB, Thio HK (2017) Probabilistic tsunami hazard analysis: multiple sources and global applications. Rev. Geophys. 55(4):1158-1198.

Grezio A, Tonini R, Sandri L, Pierdominici S, Selva J (2015) A methodology for a comprehensive probabilistic tsunami hazard assessment: Multiple sources and short- term interactions. Journal of Marine Science and Engineering. 3:23- 51.

Ichinose GA, Anderson JG, Satake K, Schweickart RA, Lahren MM (2000) The potential hazard from tsunami and seiche waves generated by large earthquakes within Lake Tahoe, California-Nevada. Geophys Res Lett. 27(8):1203-1206

Imamura F (1995) Review of tsunami simulation with a finite difference method. In Long-Wave Runup Models; World Scientific Pub Co Inc.: Singapore, pp 25-42.

Kedrinskii VK (2005) Hydrodynamics of explosion. Springer, Berlin, p 362.

Kokelaar P (1986) Magma-water interactions in subaqueous and emergent basaltic volcanism. Bull Volcanol 48:275-289

Koshimura S, Oie T, Yanagisawa H, Imamura F (2009) Developing fragility curves for tsunami damage estimation using numerical model and post-tsunami data from Banda Aceh, Indonesia, Coast. Eng. J. 51:243-273.

Le Méhauté BL (1971) Theory of explosion-generated water waves. In: Chow VT (ed) Advances in Hydroscience, vol 7. Academic Press, New York, pp 1-79

Le Méhauté BL, Wang S (1996) Water waves generated by underwater explosion. Advanced Series on Ocean Engineering 10, World Scientific Publishing, New Jersey, p 384.

Li L, Switzer AD, Chan CH, Wang Y, Weiss R, Qiu Q (2016) How heterogeneous coseismic slip affects regional probabilistic tsunami hazard assessment: A case study in the South China Sea, J. Geophys. Res. Solid Earth 121:6250-6272.

Li L, Switzer AD, Chan CH, Wang Y, Qiu Q, Weiss R (2018) A modest 0.5-m rise in sea level will double the tsunami hazard in Macau. Science Advances 4(8):1-12.

Maeno F, Imamura F (2011) Tsunami generation by a rapid entrance of pyroclastic flow into the sea during the 1883 Krakatau eruption, Indonesia. Journal of Geophysical Research: Solid Earth 116(B9), $1-24$.

Maydeu-Olivares A (2013) Goodness-of-fit assessment of item response theory models, Measurement: Interdisciplinary Research and Perspectives 11:71-101.

Mirchina NR, Pelinovsky EN (1988) Estimation of underwater eruption energy based on tsunami wave data. Nat Hazards 1:277-283 
Moore JG, Nakamura K, Alcaraz A (1966) The 1965 eruption of Taal volcano. Science 151,955-960. Morrissey M, Gisler G, Weaver R, Gittings M (2010) Numerical model of crater lake eruptions. Bull Volcanol 72:1169-1178

Myung IJ, (2003) Tutorial on maximum likelihood estimation, Journal of Mathematical Psychology 47: $90-100$.

Paris R, Ulvrova M (2019) Tsunamis generated by subaqueous volcanic explosions in Taal Caldera Lake, Philippines. Bull Volcanol 81:14.

Pakoksung K, Takagi M (2017) Mixed Zero-Inflation Method and Probability Distribution in Fitting Daily Rainfall Data. Eng. J. 21(2):63-80.

Ramos EG (2002) Origin and geologic features of Taal Lake, Philippines. Aquat Ecosyst Health Manag 5(2):155-162.

Sato H, Taniguchi H (1997) Relationship between crater size and ejecta volume of recent magmatic and phreato-magmatic eruptions: implications for energy partitioning. Geophys Res Lett 24:205-208

Suppasri A, Koshimura S, Imamura F (2011) Developing tsunami fragility curves based on the satellite remote sensing and the numerical modeling of the 2004 Indian Ocean tsunami in Thailand, Nat. Hazards Earth Syst. Sci. 11:173-189.

Suppasri A, Mas E, Charvet I, Gunasekara K, Imai K, Fukutani Y, Abe Y, Imamura F (2013) Building damage characteristics based on surveyed data and fragility curves of the 2011 Great East Japan tsunami. Nat Hazards 66:319-341.

Taddeucci J, Sottili G, Palladino DM, Ventura G, Scarlato P (2010) A note on maar eruption energetics: current models and their applications. Bull Volcanol 72:75-83.

Torsvik T, Paris R, Didenkulova I, Pelinovsky E, Belousov A, Belousova M (2010) Numerical simulation of explosive tsunami wave generation and propagation in Karymskoye Lake, Russia. Nat Hazards Earth Syst Sci. 10(11):2359-2369

Ulvrova M, Paris R, Kelfoun K, Nomikou P (2014) Numerical simulations of tsunami generated by underwater volcanic explosions at Karymskoye Lake (Kamchatka, Russia) and Kolumbo volcano (Aegean Sea, Greece). Nat Hazards Earth Syst Sci. 14:401-412

Ulvrova M, Paris R, Nomikou P, Kelfoun K, Leibrandt S, Tappin DR, McCoy FW (2016) Source of the tsunami generated by the $1650 \mathrm{AD}$ eruption of Kolumbo submarine volcano (Aegean Sea, Greece). J Volcanol Geotherm Res. 321:125-139

Valentine GA, Graettinger AH, Sonder I (2014) Explosion depths for phreatomagmatic eruptions. Geophys Res Lett. 41:3045-3051

Valentine GA, Graettinger AH, Macorps É, Ross P-S, White JDL, Döhring E, Sonder I (2015) Experiments with vertically and laterally migrating subsurface explosions with applications to the geology of phreatomagmatic and hydrothermal explosion craters and diatremes. Bull Volcanol. 77(3):1-17

Wohletz KH (1986) Explosive magma-water interactions: thermodynamics, explosion mechanisms, and field studies. Bull Volcanol. 48:245-2654 


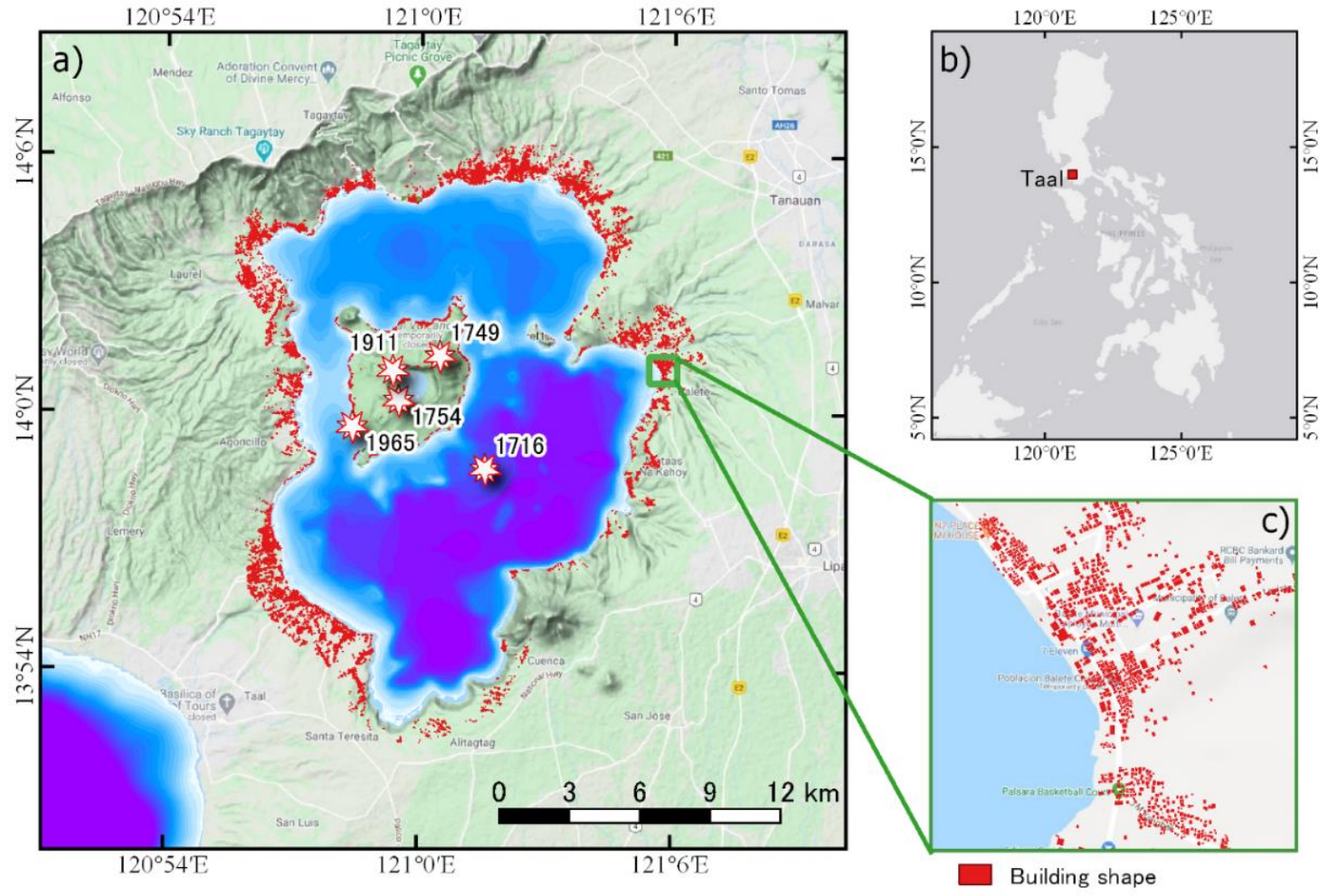

Figure 1 Location of Taal Lake and the historical eruption in the lake 

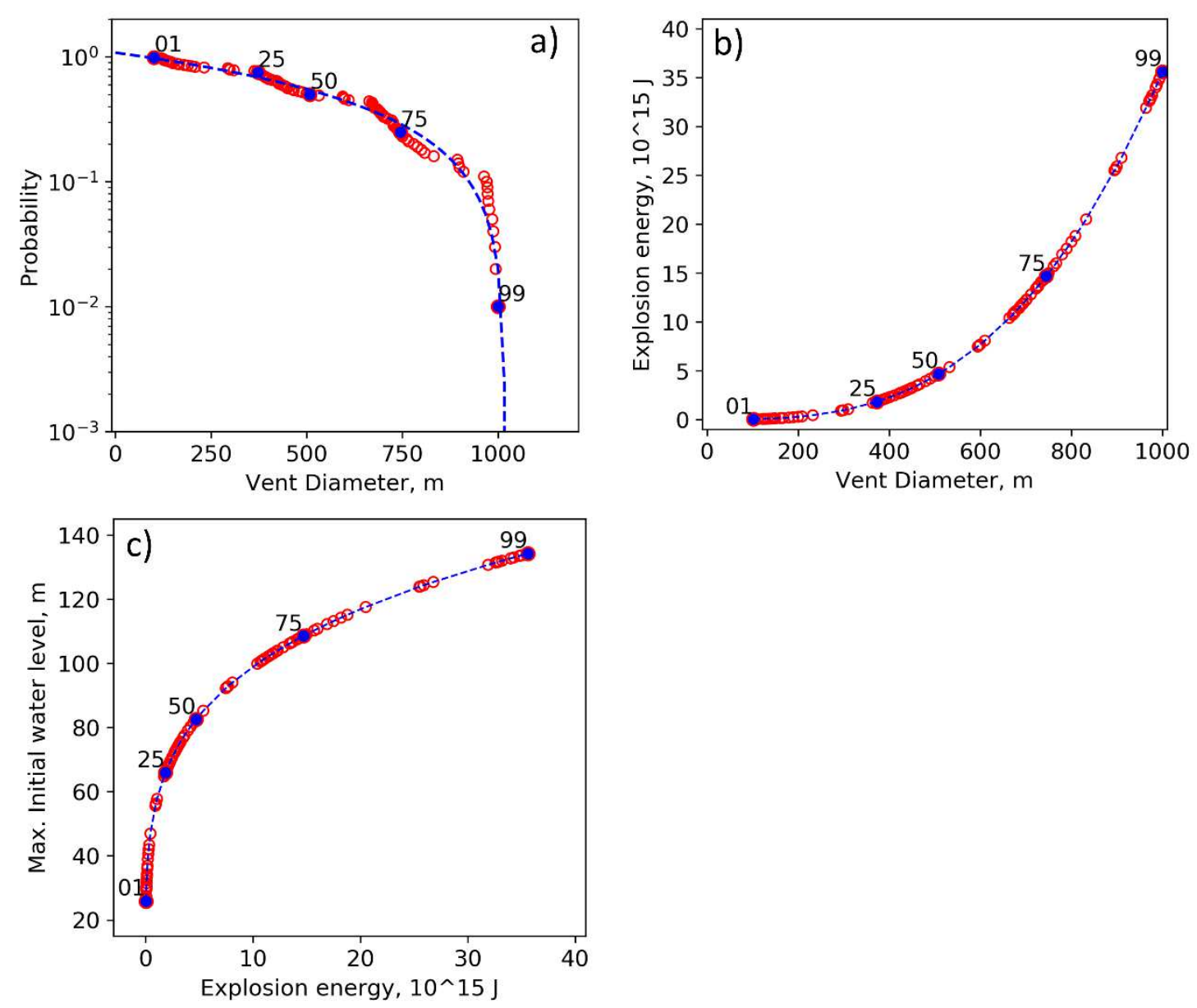

Figure 2 Scenarios of subaqueous volcanic explosions: a) probability of vent diameter (explosion size), b) the relationship between vent size and explosion energy, and c) maximum initial water level related to explosion energy. 

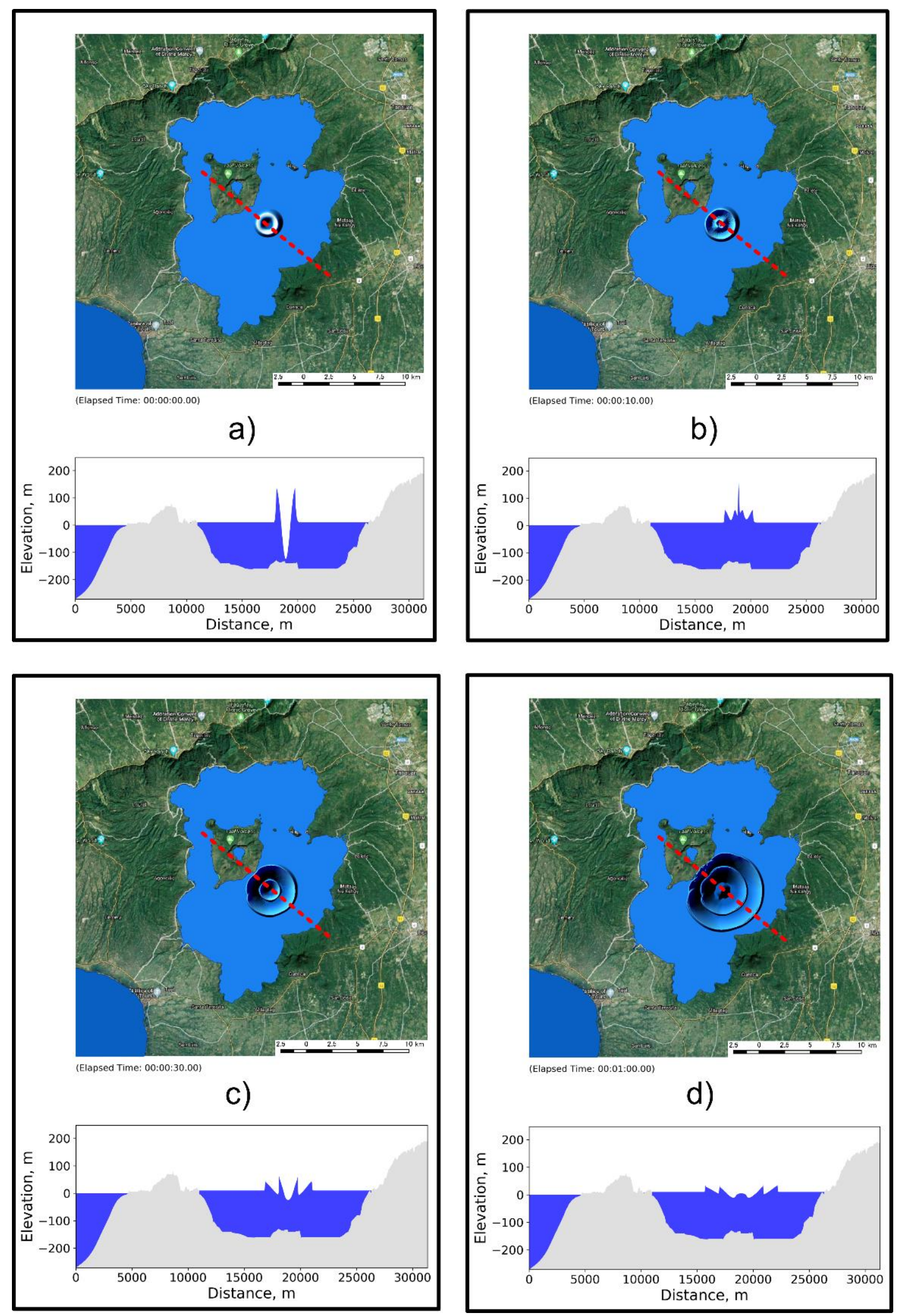

Figure 3 Tsunami generation: a) $0 \mathrm{~s}, \mathrm{~b}) 10 \mathrm{~s}$, c) $30 \mathrm{~s}$, and d) $60 \mathrm{~s}$. 

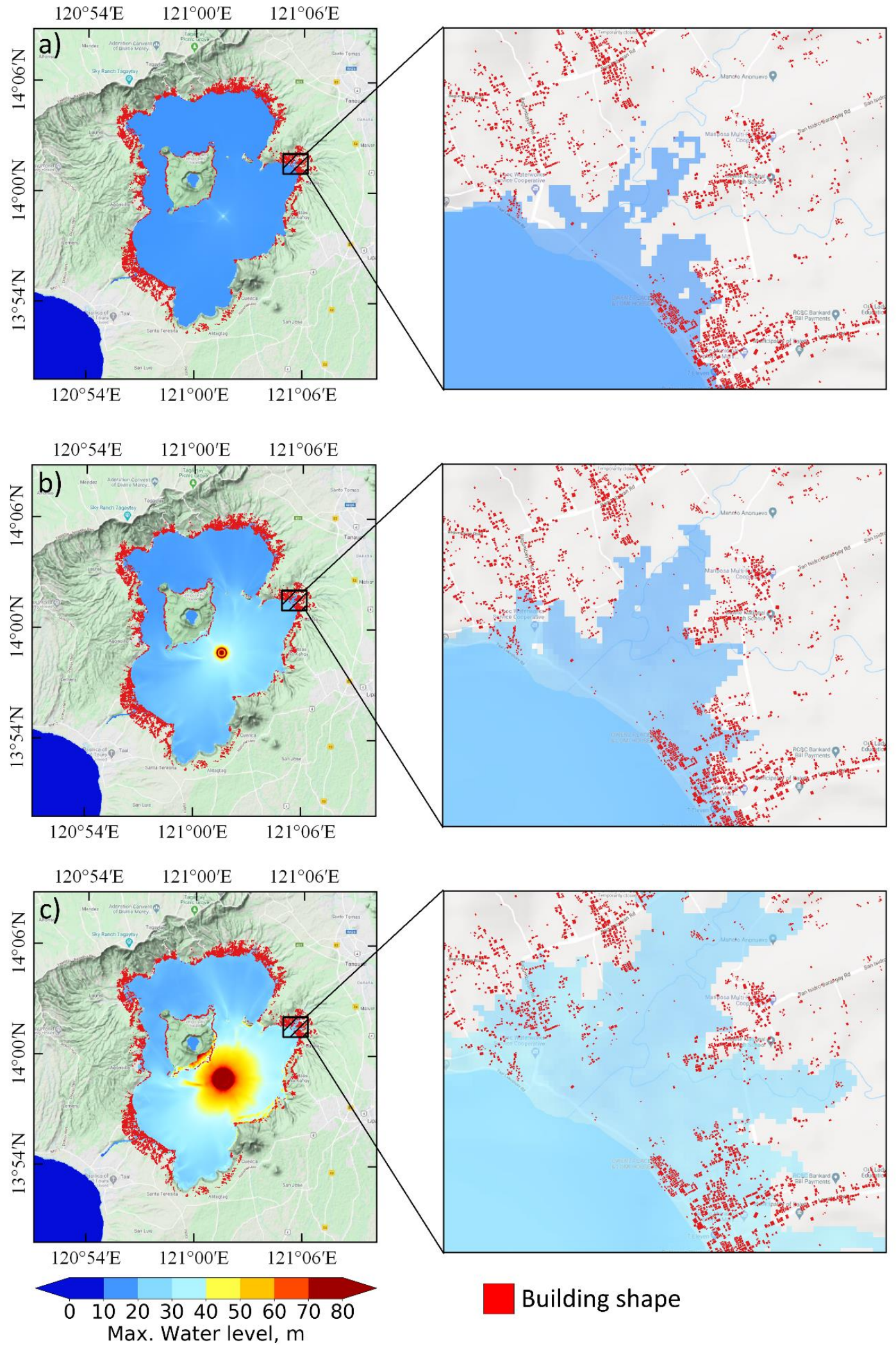

Figure 4 Maximum water level, flooded area, and an overlay on the building area: a) $1^{\text {st }}$ scenario, b) $50^{\text {th }}$ scenario, and c) $99^{\text {th }}$ scenario. 

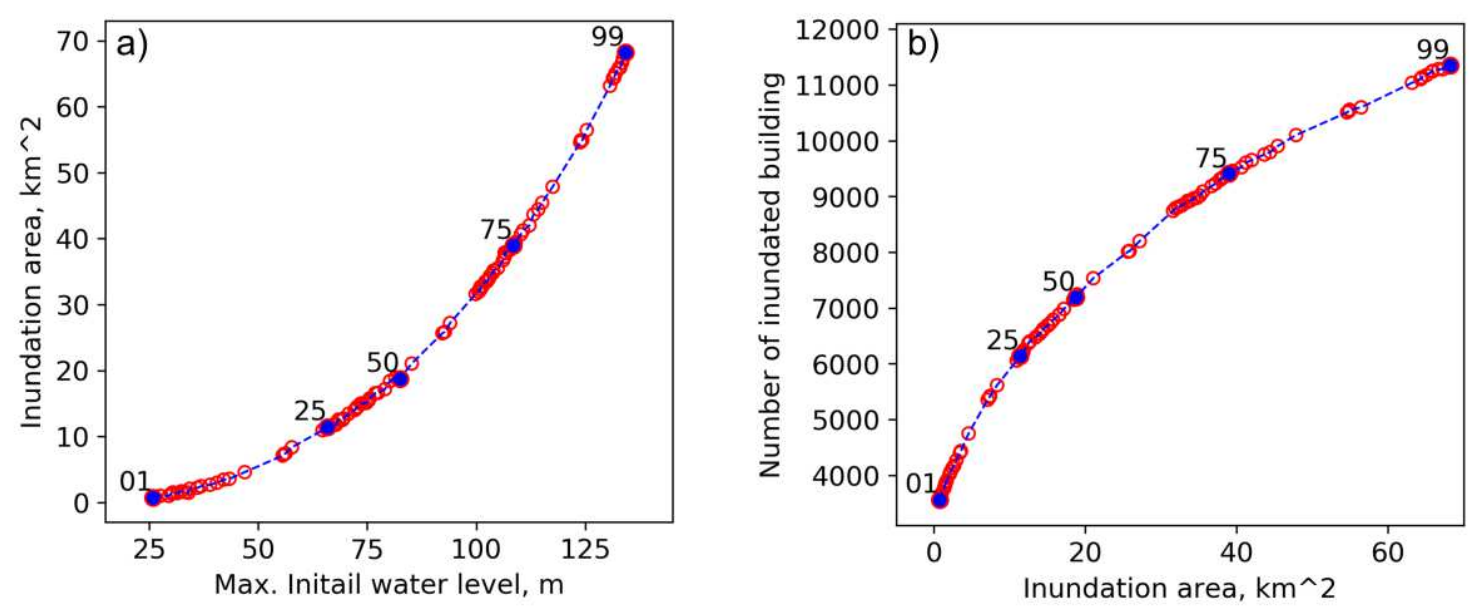

Figure 5 Results of the tsunami modeling for the different scenarios represented by the maximum initial water level and the associated inundation area and number of inundated buildings: a) the maximum initial water level creating the inundation area and $b$ ) the buildings in the inundation area. 

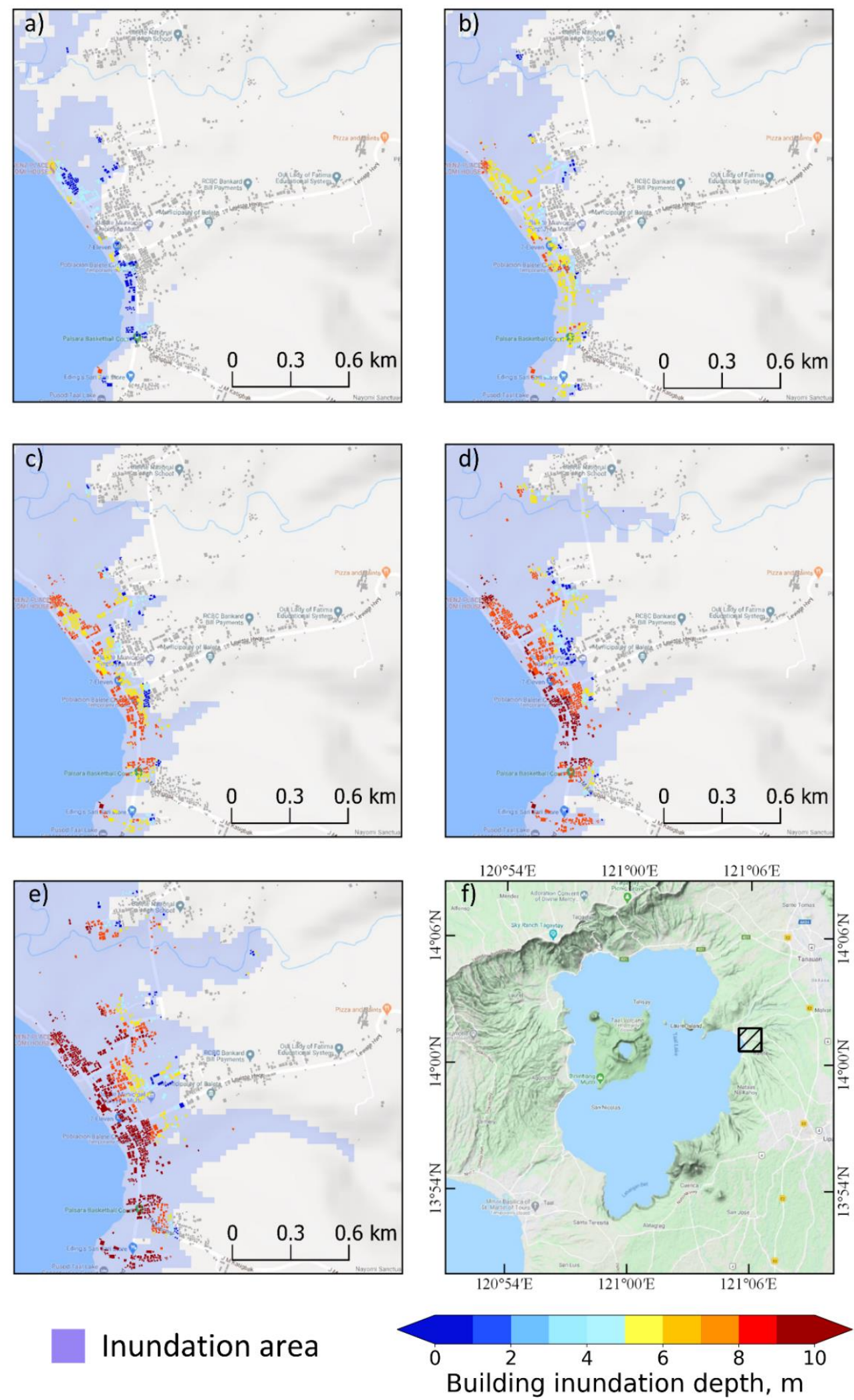

Figure 6 Hazard map for each scenario: a) $1^{\text {st }}$ scenario, b) $25^{\text {th }}$ scenario, c) $50^{\text {th }}$ scenario, d) $75^{\text {th }}$ scenario, e) $99^{\text {th }}$ scenario, and f) keymap. The presented area is located on the eastern side of the lake. 

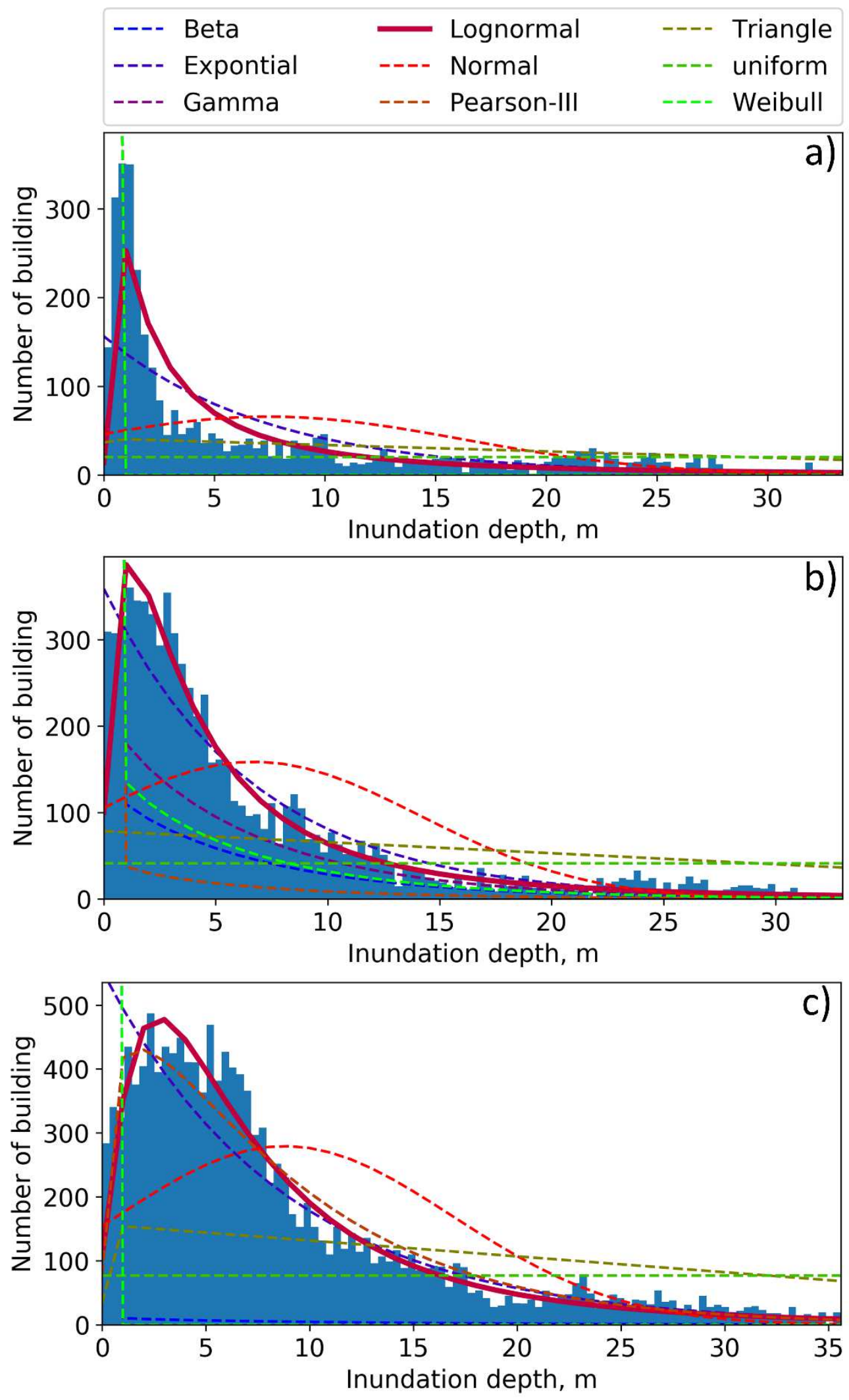

Figure 7 Number of the inundated buildings represented in a histogram and probability distribution in each candidate function, with examples of a) the $1^{\text {st }}$ scenario, b) $50^{\text {th }}$ scenario, and c) $99^{\text {th }}$ scenario. 


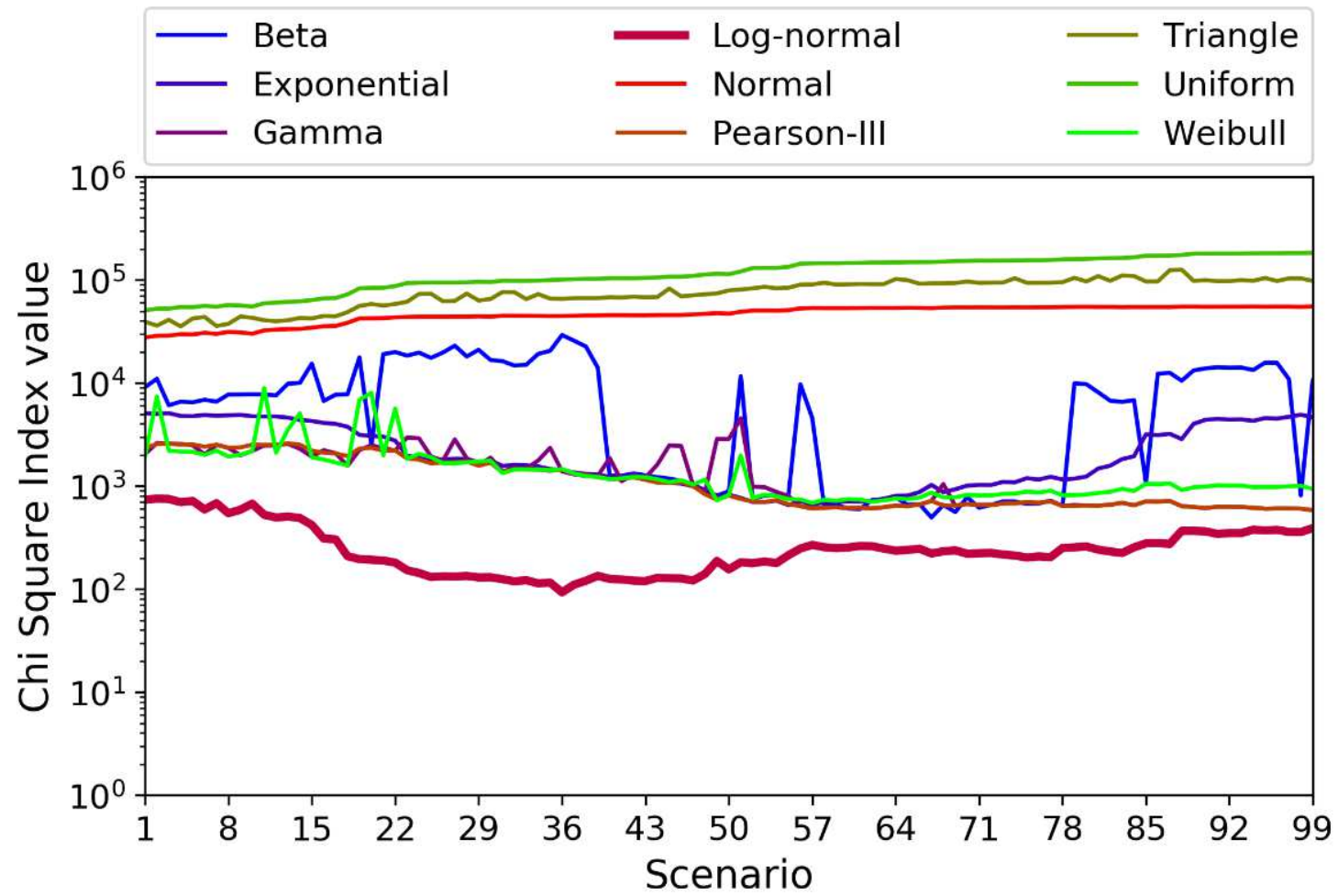

Figure 8 Chi-square test for all scenarios of the explosion in each candidate distribution.

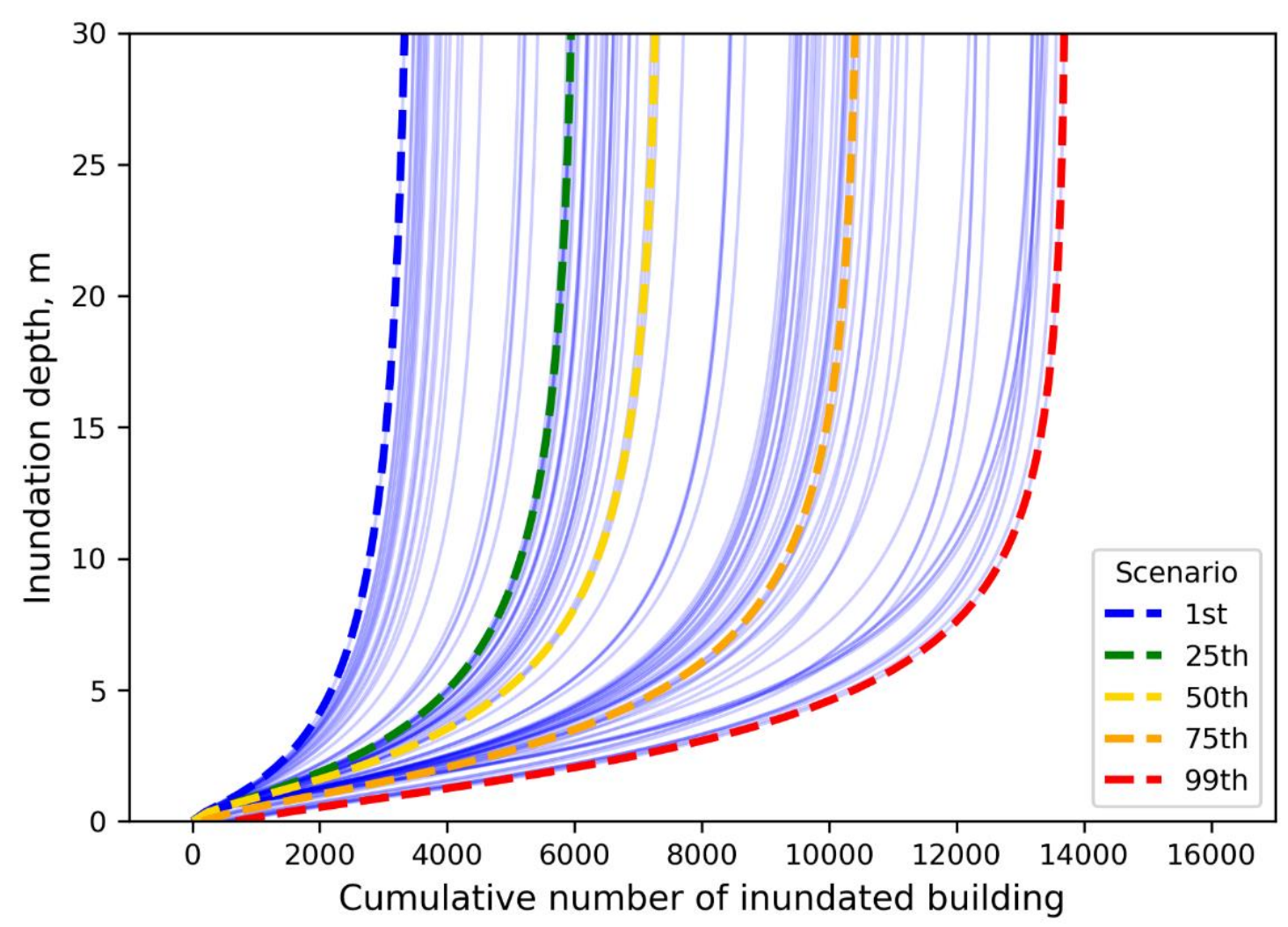

Figure 9 Hazard curve for each scenario showing the cumulative number of inundated buildings in a range of inundation depths for the whole study area. 

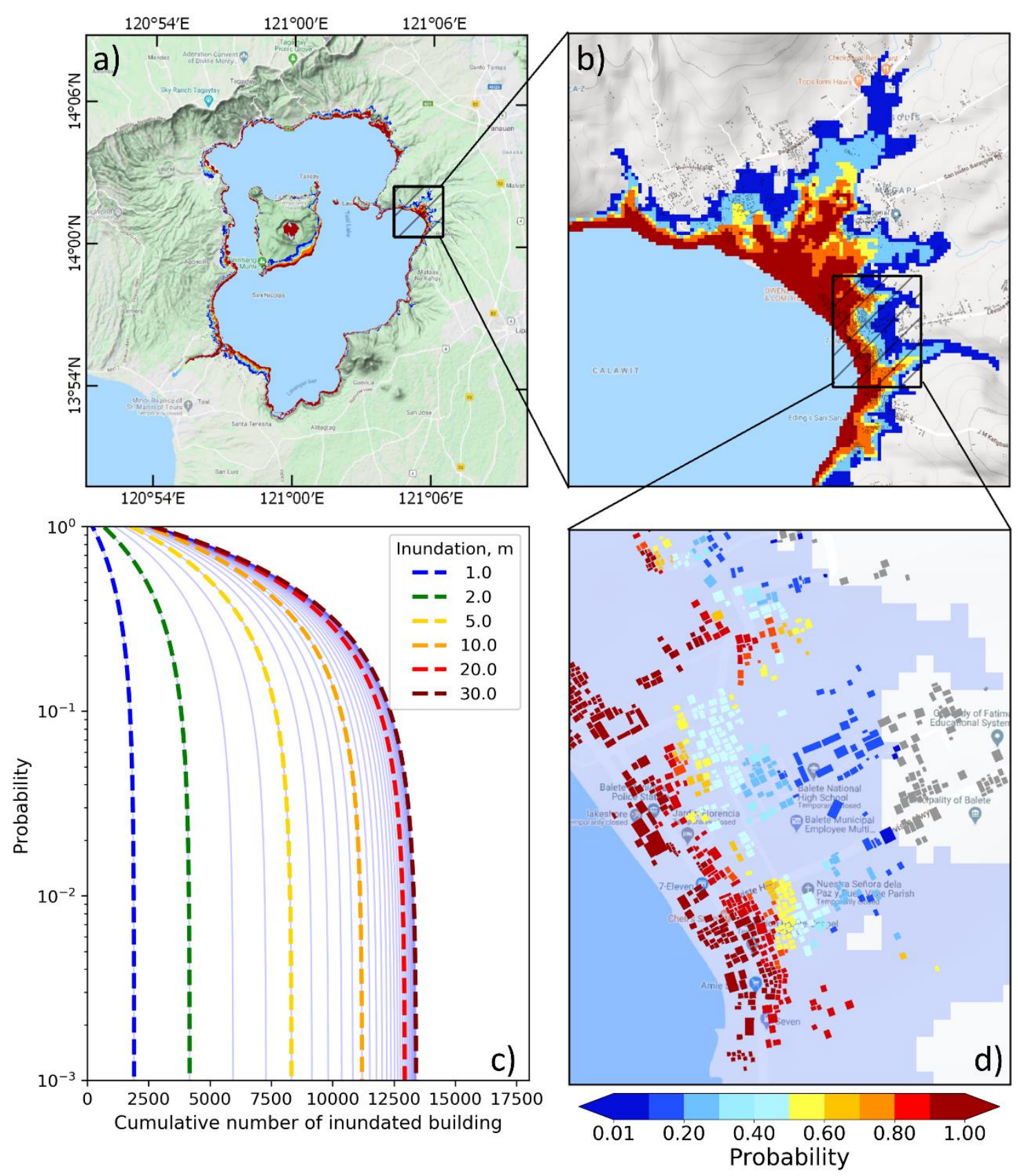

Figure 10 Tsunami hazard probability analysis in Taal Lake for a subaqueous volcanic explosion: a) tsunami hazard probability map (THPM) for the whole area, b) THPM for an example area, c) tsunami hazard probability curve of inundated buildings and d) THPM of inundated buildings. 
Figures

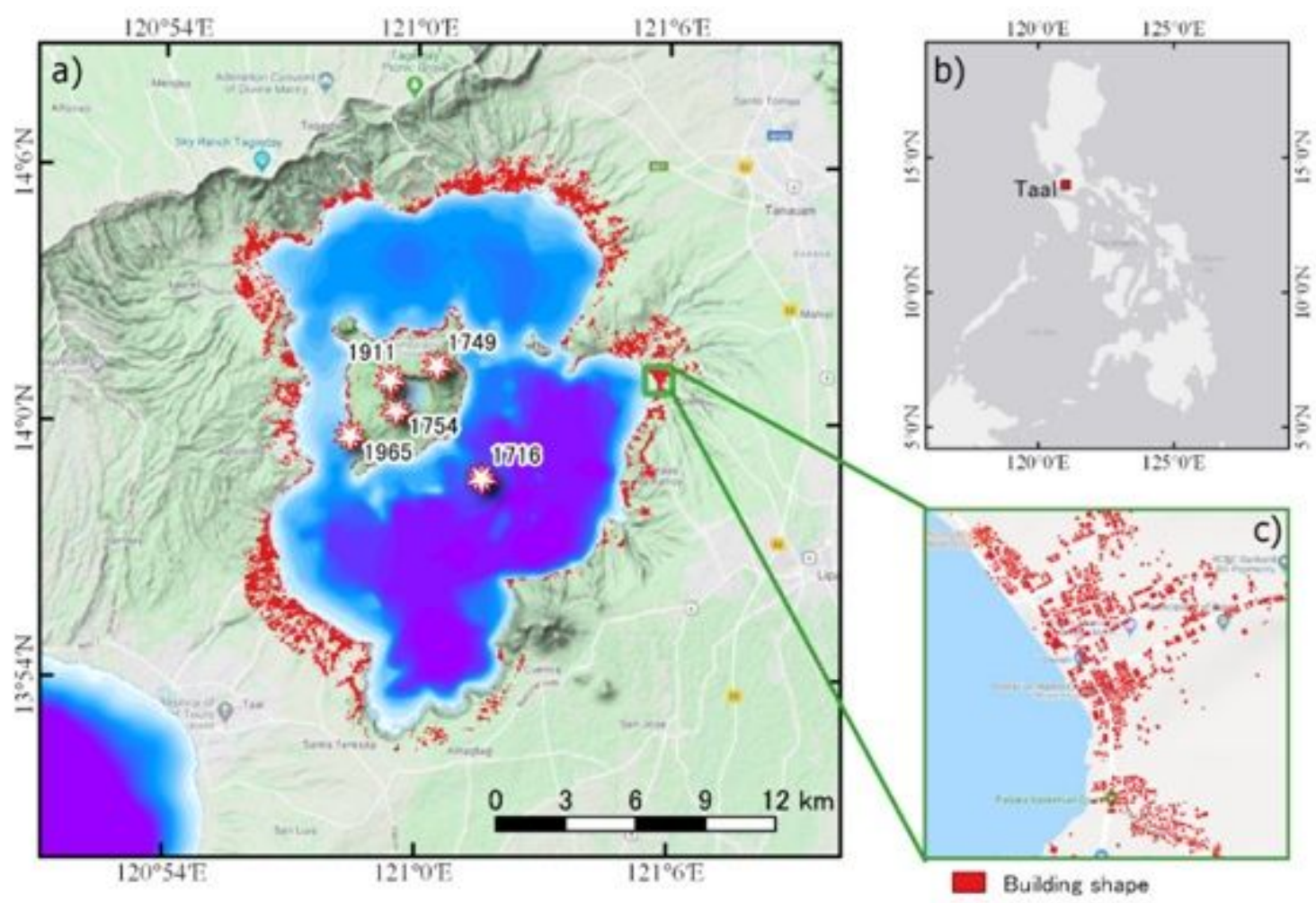

Figure 1

Location of Taal Lake and the historical eruption in the lake 

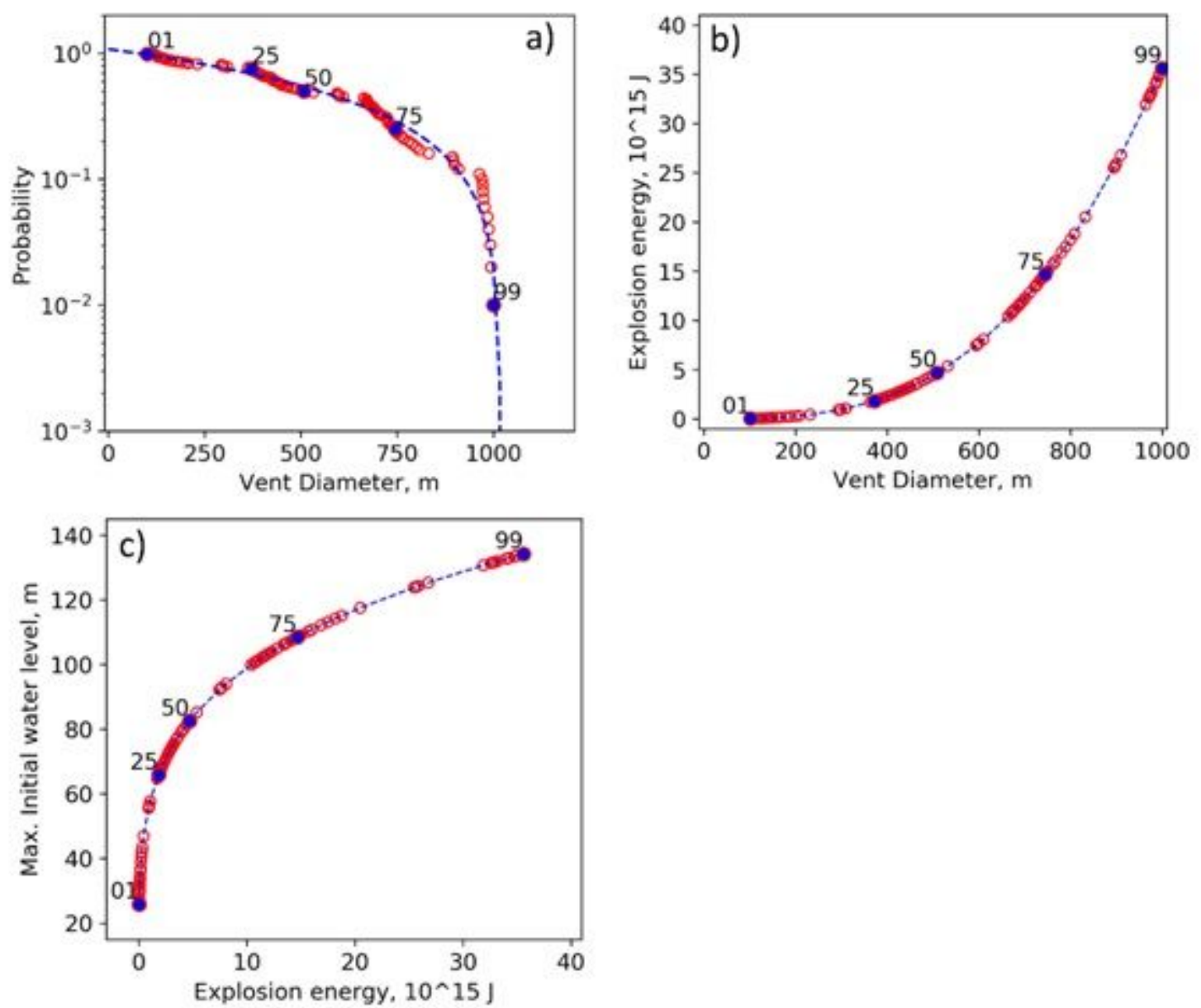

Figure 2

Scenarios of subaqueous volcanic explosions: a) probability of vent diameter (explosion size), b) the relationship between vent size and explosion energy, and c) maximum initial water level related to explosion energy. 

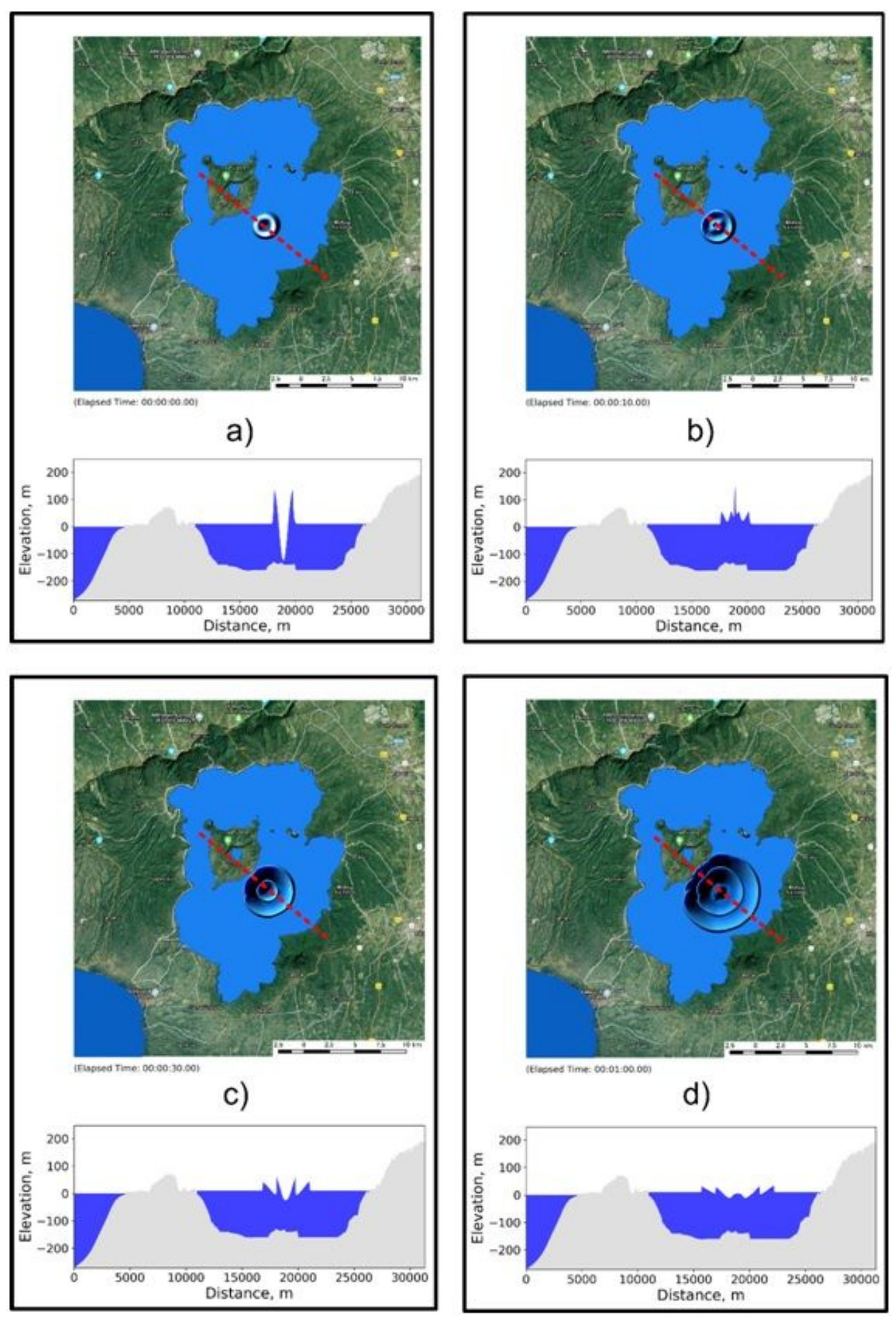

Figure 3

Tsunami generation: a) $0 \mathrm{~s}$, b) $10 \mathrm{~s}$, c) $30 \mathrm{~s}$, and d) $60 \mathrm{~s}$. 

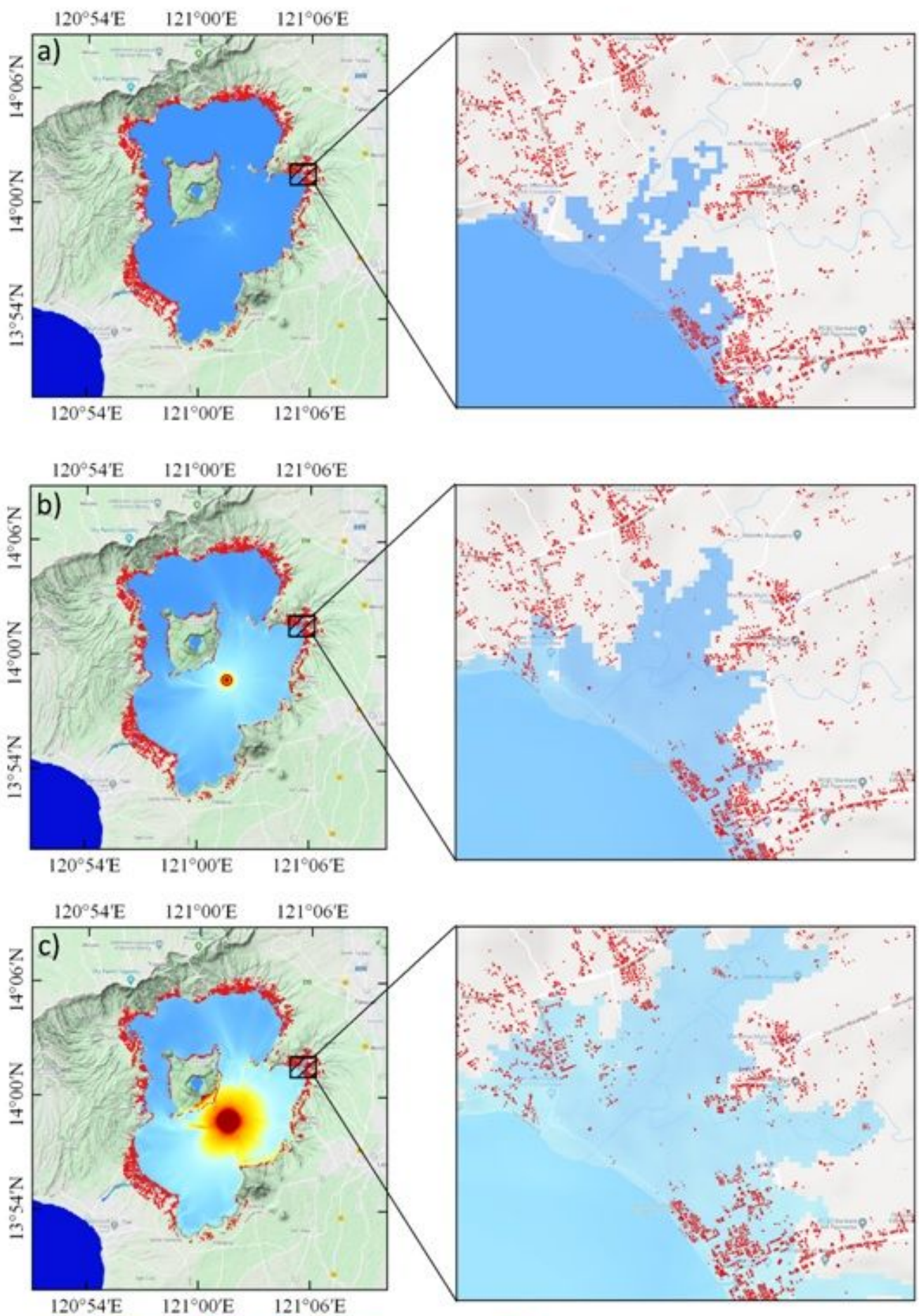

$120^{\circ} 54^{\prime} \mathrm{E} \quad 121^{\circ} 00^{\prime} \mathrm{E} \quad 121^{\circ} 06^{\prime} \mathrm{E}$

01020304050607080

Building shape

Max. Water level, $\mathrm{m}$

Figure 4

Maximum water level, flooded area, and an overlay on the building area:a) 1st scenario, b) 50thscenario, and c) 99th scenario. 

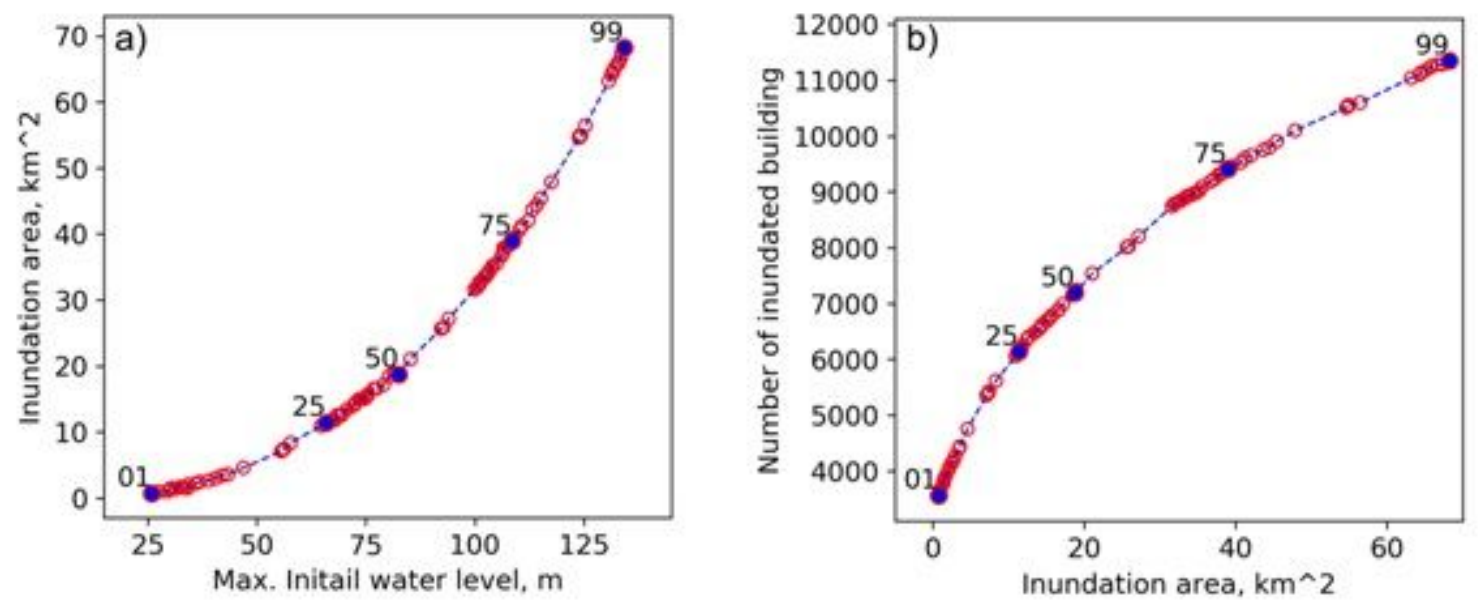

Figure 5

Results of the tsunami modeling forthe different scenarios represented by the maximum initial water level and the associated inundation area and number of inundated buildings: a) the maximum initial water level creating the inundation area and $b$ ) the buildings in the inundation area. 

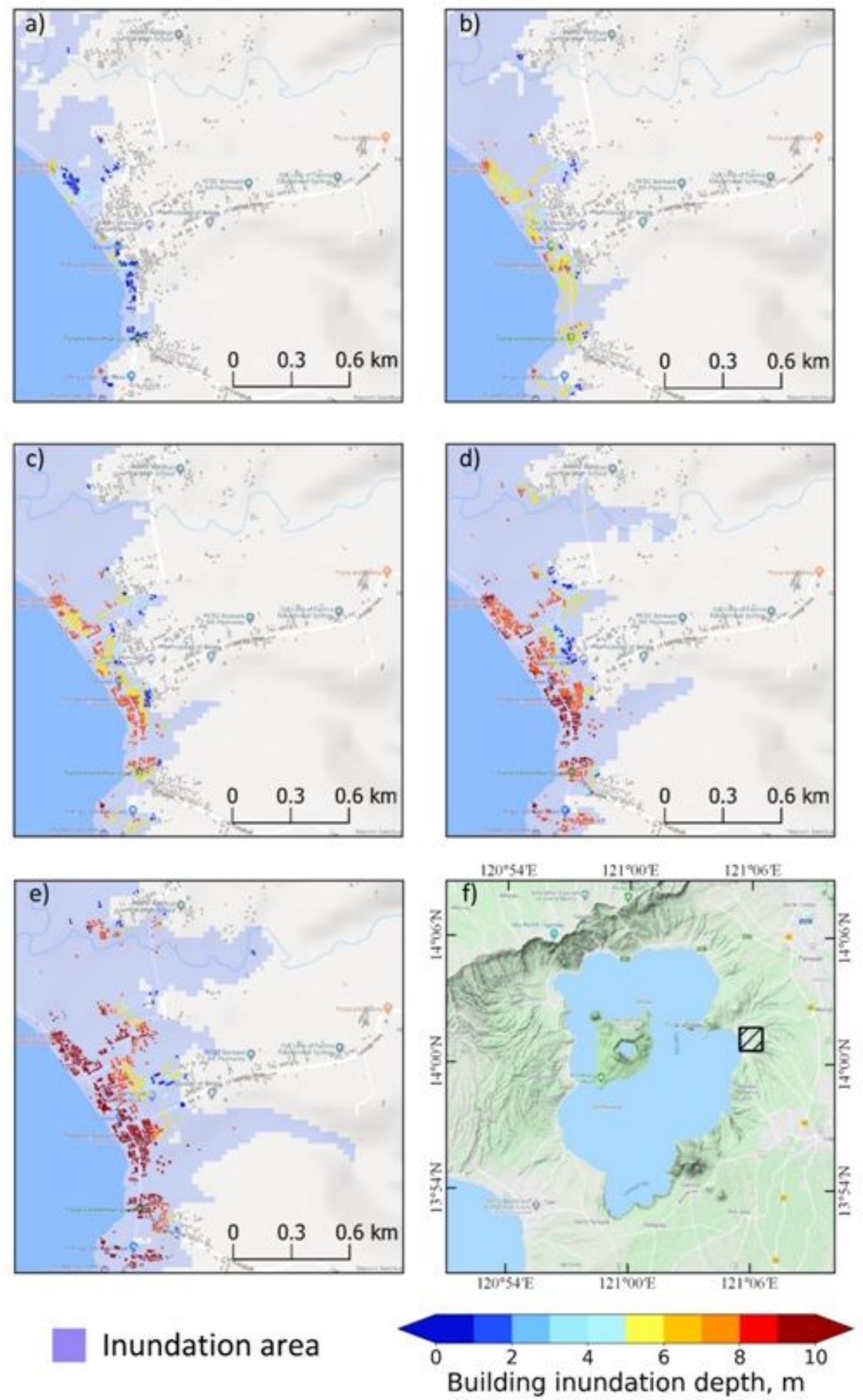

\section{Figure 6}

Hazard map foreach scenario: a) 1st scenario, b) 25thscenario, c) 50thscenario, d) 75thscenario, e) 99th scenario, and f) keymap. The presented area is located on the eastern side of the lake. 

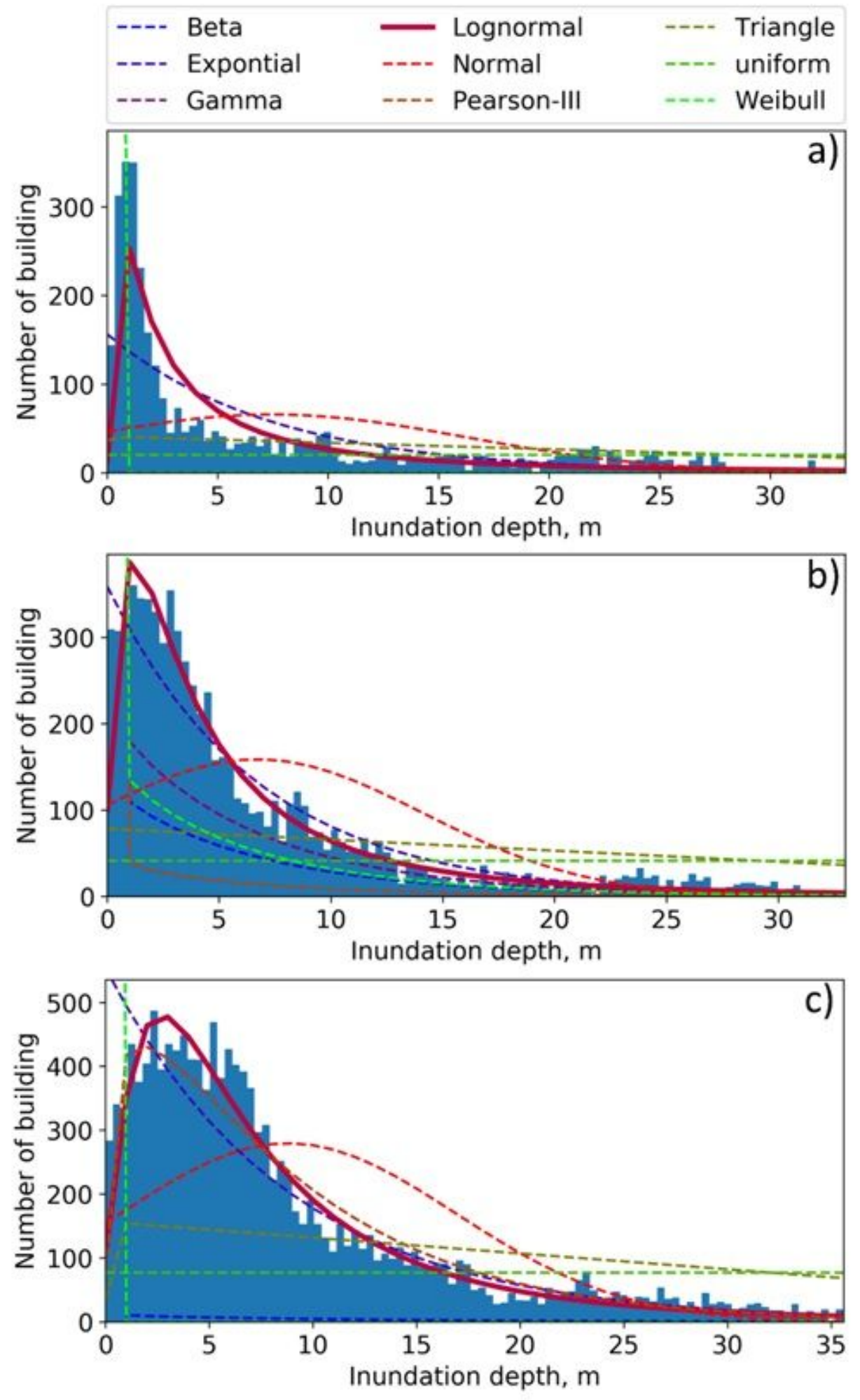

Figure 7

Number of the inundated buildings represented in ahistogram and probability distribution in each candidate function, with examples of a) the 1st scenario, b) 50thscenario, and c) 99th scenario. 


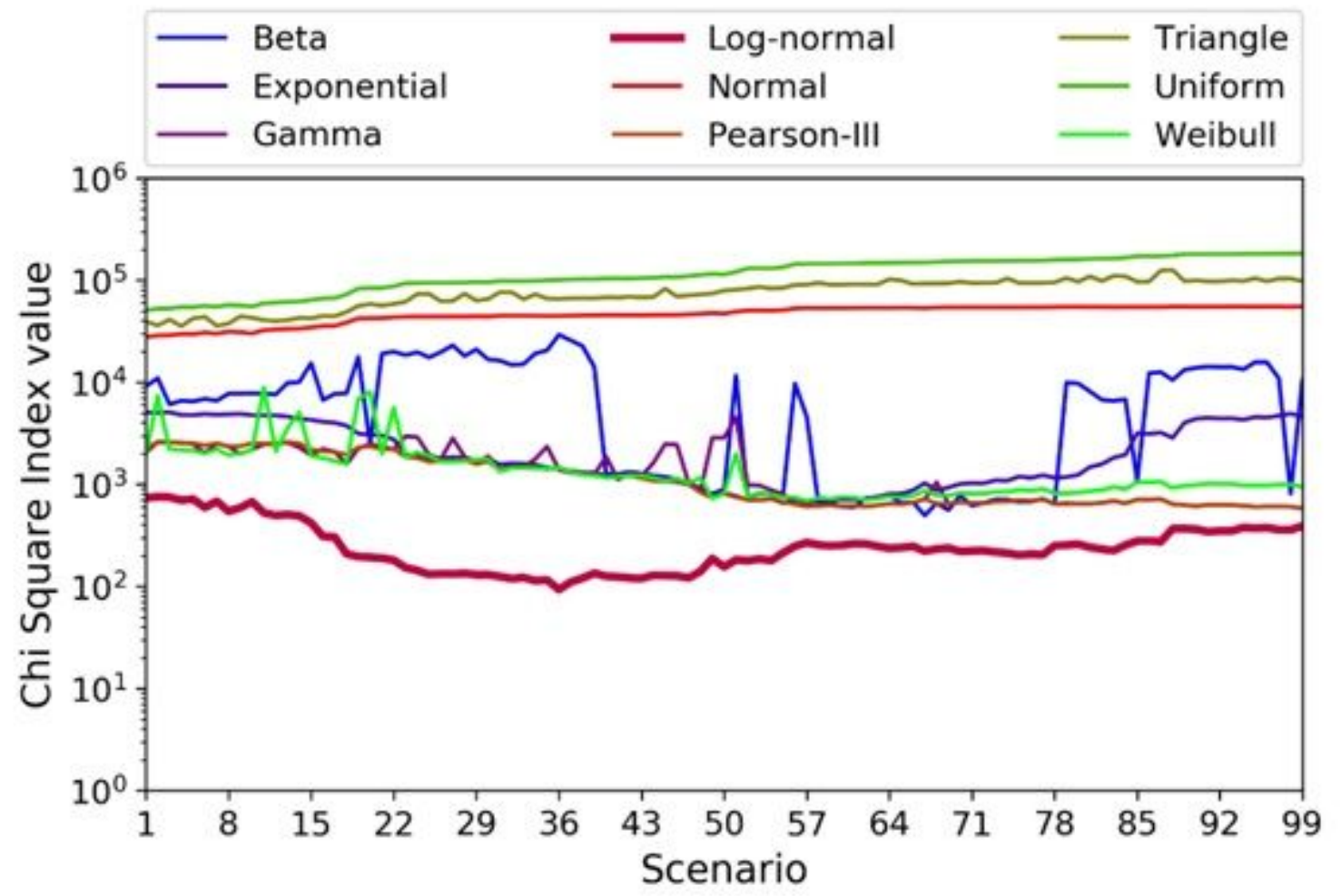

Figure 8

Chi-square test for all scenarios of the explosion in each candidate distribution.

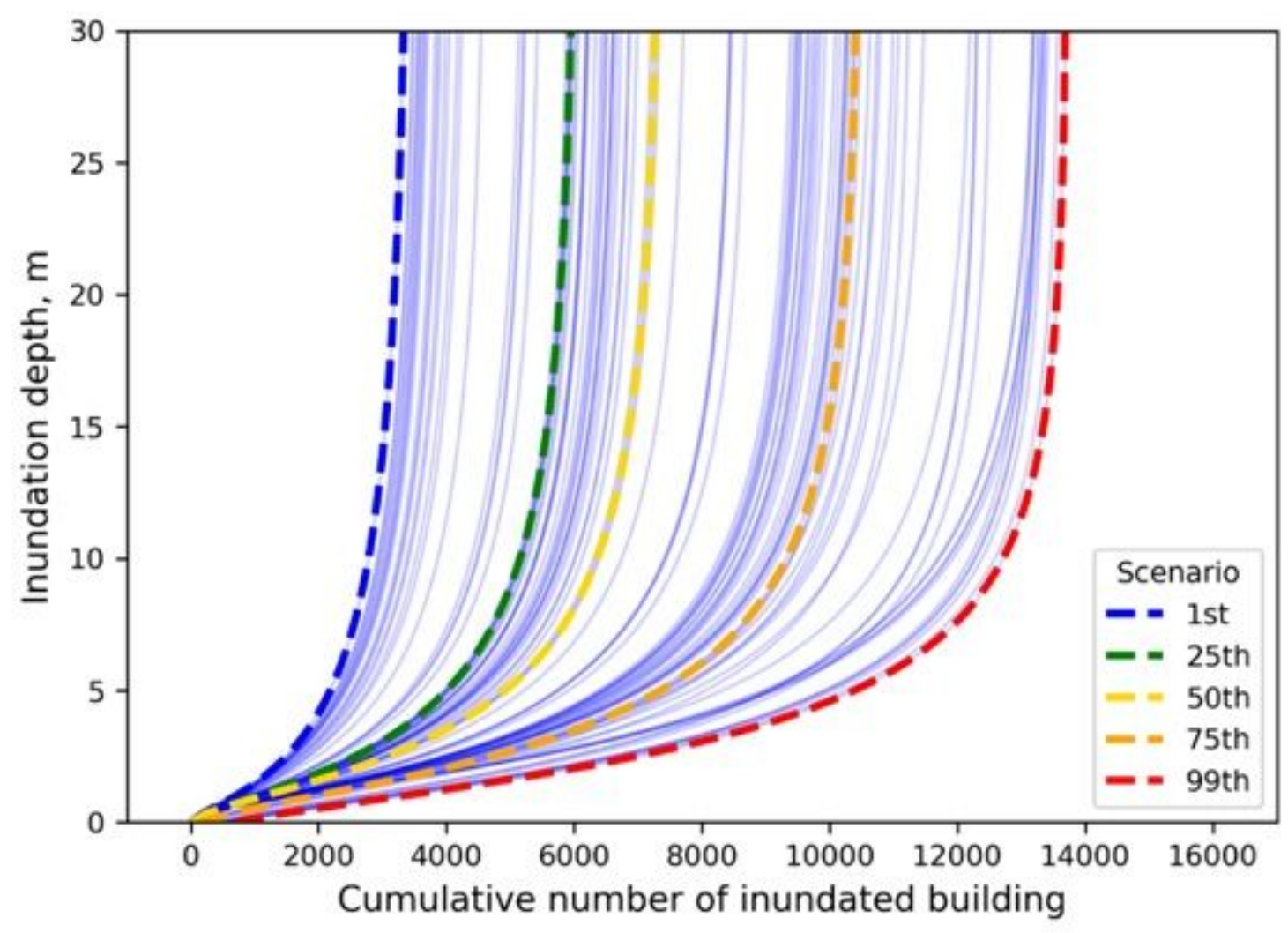

Figure 9 
Hazard curve foreach scenario showing the cumulative number of inundated buildings in a range of inundation depthsfor thewhole study area.

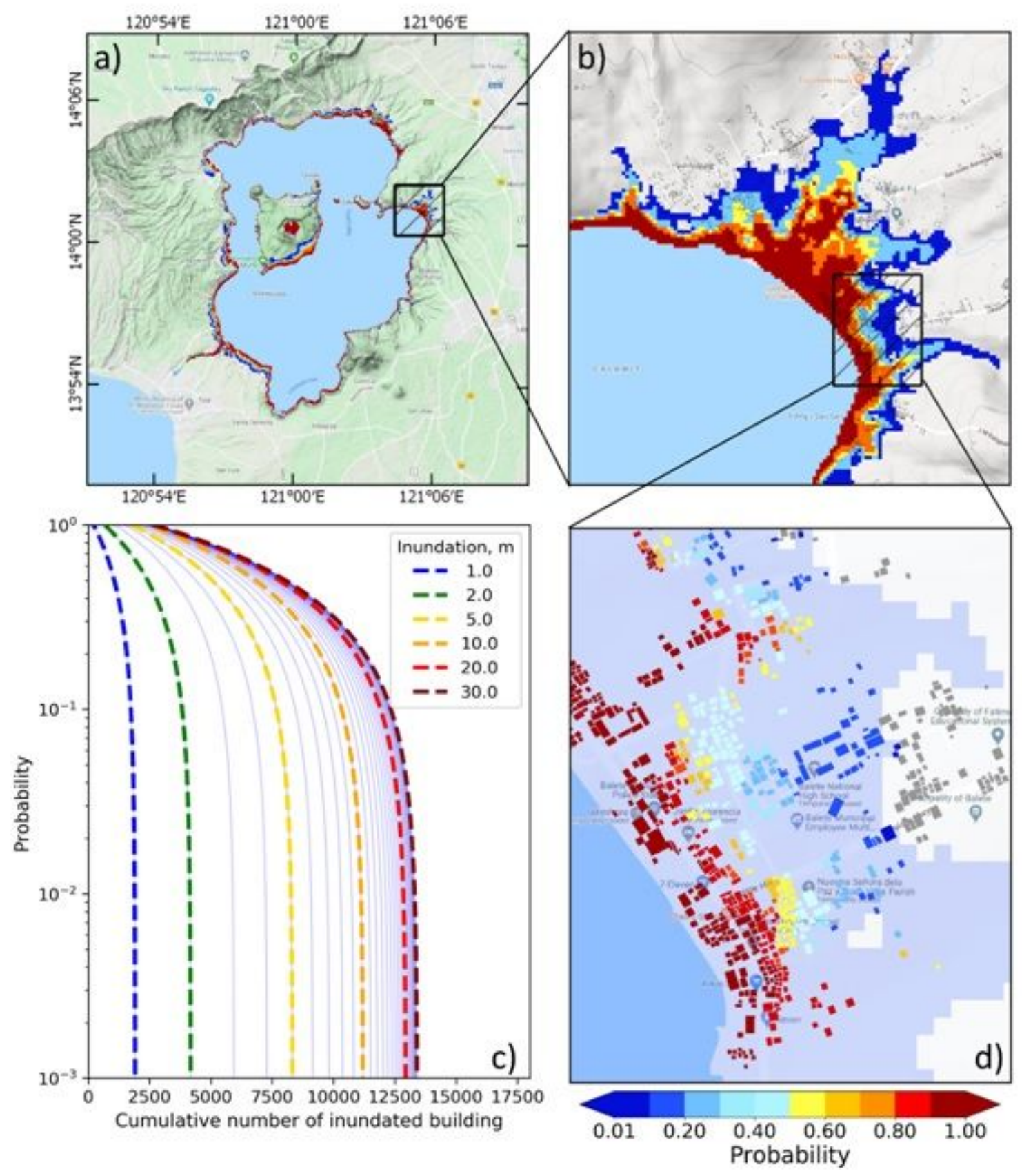

\section{Figure 10}

Tsunami hazard probability analysis in Taal Lake for asubaqueous volcanic explosion: a) tsunami hazard probabilitymap (THPM) forthe whole area, b) THPM foranexample area, c) tsunami hazard probabilitycurve of inundated buildings and d) THPMof inundated buildings.

\section{Supplementary Files}

This is a list of supplementary files associated with this preprint. Click to download. 
- JSTNK16X4D3B9172081BD6084FBP.pdf 